\title{
Landslide investigation using Seismic Refraction Tomography method: a review
}

\author{
Parisa Imani ${ }^{1,2}$, Amr Abd EL-Raouf*,1,3 and Gang Tian ${ }^{1}$ \\ (1) School of Earth Sciences, Zhejiang University, Hangzhou, China \\ (2) School of Mining, Petroleum and Geophysics Engineering, Shahrood University of Technology, Shahrood, Iran \\ (3) Geology Department, Faculty of Science, Zagazig University, Zagazig, Egypt
}

Article history: received January 26, 2021; accepted September 20, 2021

\begin{abstract}
Since the early 1960s, the near-surface seismic refraction method has been extensively used as a non-invasive and cost-effective geophysical method to characterize geological structures for landslide investigation. Seismic refraction tomography (SRT) is considered a modern interpreting seismic refraction data that allows for determining lateral variations of P-wave velocity. This geophysical technique can characterize the slope material, the sliding surface's geometry, the landslide mass movement, the physical properties of media, and the water saturation effects on the slope. Therefore, this method has become an appropriate method due to the increasing progress of novel algorithms and the improvements of field-data collection systems. This paper reviews the essential research investigating various types of landslides influenced by water saturation and landslide materials and identified in various areas since 2000. Significant conclusions obtained by applying different survey strategies and data processing algorithms in seismic refraction surveys are widely discussed, concentrating on the advantages and disadvantages of this method. The main results obtained by the few time-lapse SRT (TLSRT) are mainly analyzed.
\end{abstract}

Keywords: Landslide; Near-surface; Seismic refraction tomography (SRT); Time-lapse SRT (TLSRT); Monitoring.

\section{Introduction}

Landslides are the mass movement of debris, rock, and earth downslope. They are considered one of the natural hazards in many parts of the world. Landslides cause losses of lives and properties [Perrone et al., 2014]. They are triggered by different mechanisms (e.g., typhoons, precipitation, and earthquakes) [Heincke, 2005]. Most of them occur on unstable slopes caused by meteorological events that increase the probability of slope failures [Göktürkler et al., 2008; Imani et al., 2021a; Imani et al., 2021b; Kul Yahşi and Ersoy, 2018; Ozcep et al., 2012; Samyn et al., 2012; Yilmaz and Kamaci, 2018]. The detection and characterization of landslide bodies require a multidisciplinary method based on combined geotechnical techniques, geophysical surveys, geological setting investigations, ground-based approaches, and airborne approaches. However, the geotechnical and geological approaches cannot be applied for investigating the subsurface structures; instead, they are typically used in investigating borehole samples and surface structures [Heincke, 2005]. 


\section{Parisa Imani et al.}

Airborne and remote sensing approaches aim at improving landslide investigations with their ability to analyze prior events; monitor surface changes, such as outcrop failures, displacements, geomorphologic settings during a specific period, and landslide activities; and evaluate landslide susceptible regions [Mantovani et al., 1996; Metternicht et al., 2005; Scaioni et al., 2014]. Scaioni et al. [2014] categorized the remote sensing methods into four classifications: passive optical sensors, thermal infrared remote sensing, microwave sensors, and airborne and terrestrial laser scanning. Ventura et al. [2011] applied multi-temporal airborne light detection and ranging (lidar) data to investigate complex landslides in Southern Italy. A combination of lidar and inclinometer information could produce 3D images of the rockfall site's surficial and inner kinematics [Tomás et al., 2018]. Baldi et al. [2008] used archival photogrammetry and global positioning system (GPS) data on landslide kinematics. The tiltmeter, conventional inclinometer, and piezometer are other tools applied to the regions influenced by landslide events to characterize the subsoil's hydraulic and mechanical properties [Perrone et al., 2014; Uhlemann et al., 2016] at a certain point. Despite all the capabilities of ground-based and airborne methods, they are not able to study the characterization of subsurface materials and the lateral extent.

The application of near-surface geophysical techniques has extensively increased. These methods can give reliable results obtained from the slope with a non-invasive, quick, and user-friendly technology [Al-Saigh and AlDabbagh, 2010; Bekler et al., 2011; Bichler et al., 2004; Capizzi and Martorana, 2014; Chen et al., 2019b; Donohue et al., 2012; Ferrucci et al., 2000; Göktürkler et al., 2008; Grit and Kanli, 2016; Havenith et al., 2002; Havenith et al., 2000; Imani et al., 2021a; Imani et al., 2021b; Jacob et al., 2018; Jongmans et al., 2009; Jongmans and Garambois, 2007; Karslı et al., 2017; Kim et al., 2011; Kul Yahşi and Ersoy, 2018; Mauritsch et al., 2000; Mezerreg et al., 2019; Ng et al., 2015; Nwankwo and Ugbena, 2019; Otto and Sass, 2006; Ozcep et al., 2012; Samyn et al., 2012; Solberg et al., 2012; Tomás et al., 2018; Travelletti et al., 2010; Wang et al., 2016; Yilmaz and Kamaci, 2018]. Geophysical techniques can locate the water content and assess the volume of the landslide body and the physical properties of landslide materials. The selected investigation methods depend on the contrasts of the physical parameters. For investigating other parameters, such as the landslide volume, morphology, and penetration depth, the equipment set up on the investigation area should be accurately considered [Jongmans and Garambois, 2007].

Geophysical procedures can characterize a large volume of subsurface materials by overcoming specific point measurements. Although the conventional seismic refraction method is frequently employed in landslide studies because of the availability of the factors that influence seismic velocities and spatially and temporally diversify them, the seismic refraction tomography (SRT) method is considered as the most commonly used geophysical technique in landslide investigations with high-resolution illustrations [Hack, 2000; McCann and Forster, 1990]. This technique is significantly applied as a modern geophysical procedure of interpreting seismic refraction data that employ forward and inversion modeling methods to estimate the velocity in 2D and 3D surveys [Al-Heety and Shanshal, 2015]. The SRT allows the interpretation of velocity variations as gradient and discrete layers [Azwin et al., 2013]. This method measures the subsurface seismic velocities and depicts images of underground geological settings. In general, seismic velocity is affected by the rock properties, such as the water saturation, material compositions, weathering rate, and porosity volume [Bogoslovsky and Ogilvy, 1977; Kaminskiy, 2013; Kassab and Weller, 2015]. Among these factors, the water content and porosity play an essential role in increasing the pore water pressure, reducing the shear strength, and finally triggering the landslide [Imani, 2020; Imani et al., 2021b; $\mathrm{Xu}$ et al., 2016; Yalcin, 2007]. These are the specific reasons for applying seismic refraction tomography to characterize landslide materials' physical properties and delineate the boundaries and surface failures. To have a successful seismic refraction project with useful and reliable results, great attention should be paid to the survey strategy and data processing algorithm to be performed on the specific landslide type and materials. The survey layout should be designated to cover the considered area extensively and to suit the lithological, geological, and topographic conditions of the study area. Additionally, the algorithm processing data should be able to separate noises from the signals carrying subsoil information and to present the subsurface model with a high resolution and no ambiguity.

In most landslide studies, seismic refraction methods are integrated with other geophysical techniques to obtain accurate and reliable results from heterogeneous landslide structures. The expected contrast of the physical properties, penetration depth, accuracy, landslide characteristics, and economic factors allow the researchers to choose a suitable geophysical method to combine with the SRT technique. Hack [2000] used various types of geophysical methods to investigate slope stability. He concluded that using the combined methods helped to detect different subsurface structures that were impossible to visualize using a single method. 
McCann and Forster [1990] applied several surface geophysical methods, such as seismic refraction, microseismic monitoring, electrical resistivity, the magnetic method, electromagnetic surveys, and boreholes, to illustrate the geometry of landslides, to characterize the mass movements, and to detect the hydrogeological regime and water content. Bárta et al. [2005] surveyed the Sudety Mountains using seismic and dynamic tests, gravity measurements, natural electric fields, the resistivity method, and ground-penetrating radar (GPR). There are no obvious conclusions from this paper; however, they had an excellent experience using resistivity tomography. Baron and Supper [2013] studied in 14 European and Asian countries using lidar airborne laser scanners (ALS), geophysical logging, aerial imaging, resistivity measurements, ground-based synthetic aperture radar interferometer (GB InSAR), and the seismic refraction method. Based on this study, the electromagnetic (EM) method, seismic survey, and DC resistivity were the most reliable geophysical techniques for landslide investigation. Despite the use of combined methods, SRT technique is of great importance in landslide studies.

The current study presents the results of landslide research articles, mainly focused on detecting water contents, published in valid journals and research dissertations applying seismic refraction tomography method (SRT) since 2000. This paper is concentrated explicitly on various data acquisition systems and data processing methods for different landslide typologies. The present research recognizes the limitations and potentials of the refraction method in landslide studies.

\section{Materials and Methods}

\subsection{Application of Seismic Refraction Tomography in Landslide Investigation}

Since the early 1960s, the seismic refraction method has been considered one of the most commonly used techniques in near-surface geophysical projects, particularly in landslide studies [Armstrong et al., 2011; Hack, 2000]. Since the SRT indicates the subsurface materials as continuous media where the first break recorded does not strictly depend on materials or refractors with a high contrast of velocities [Rucker, 2000], the refraction tomography is ideal for characterizing the area with strong gradients of lateral velocities. The seismic refraction tomography can be applied in high precipitation zones to provide the subsoil images based on seismic velocity increasing at greater depths. The velocity illustrations are analyzed and interpreted according to velocity contrasts, which are chiefly caused by various lithologies and variations in water saturation. In other words, determining the landslide lateral extension and depth and distinguishing the boundaries among subsurface horizons of lithologies characterized by increasing wave velocity affected by different densities are the main tasks of the SRT approach [Bekler et al., 2011; Bogoslovsky and Ogilvy, 1977; Brooke, 1973; Narwold and Owen, 2002; Palmer and Weisgarber, 1988]. In the field procedure, the seismic signals travel down through the earth and refract and diffract from discontinuities due to the increasing velocity with depth [Göktürkler et al., 2008]. Reducing the rigidity of the landslide mass and the presence of fractures decreases the seismic velocity propagating through the landslide body [Cummings and Clark, 1988]. Based on the obtained results by Bogoslovsky and Ogilvy [1977] and Otto and Sass [2006], the seismic velocity as the mechanical property of landslides can characterize the materials and delineate the failure surface due to the nature of lithological features and the contrast among various kinds of media.

The SRT can also illustrate the subsoil slopes. The slope investigations can be hard to survey due to placing the geophones and sources in the access points; however, a seismic refraction technique can be performed easier on such conditions [Hack, 2000]. However, state-of-the-art studies accomplished on slope deformation, regardless of the type of landslides, applied seismic refraction as the preferred geophysical method [Pazzi et al., 2019].

The current review represents the most useful information from the investigated studies in Table 1. This Table reports the research studies in detail, including the first author's name, the journal-title, the publication year, the landslide typology, the geological setting of sites, the processing approach, etc. 
Parisa Imani et al.

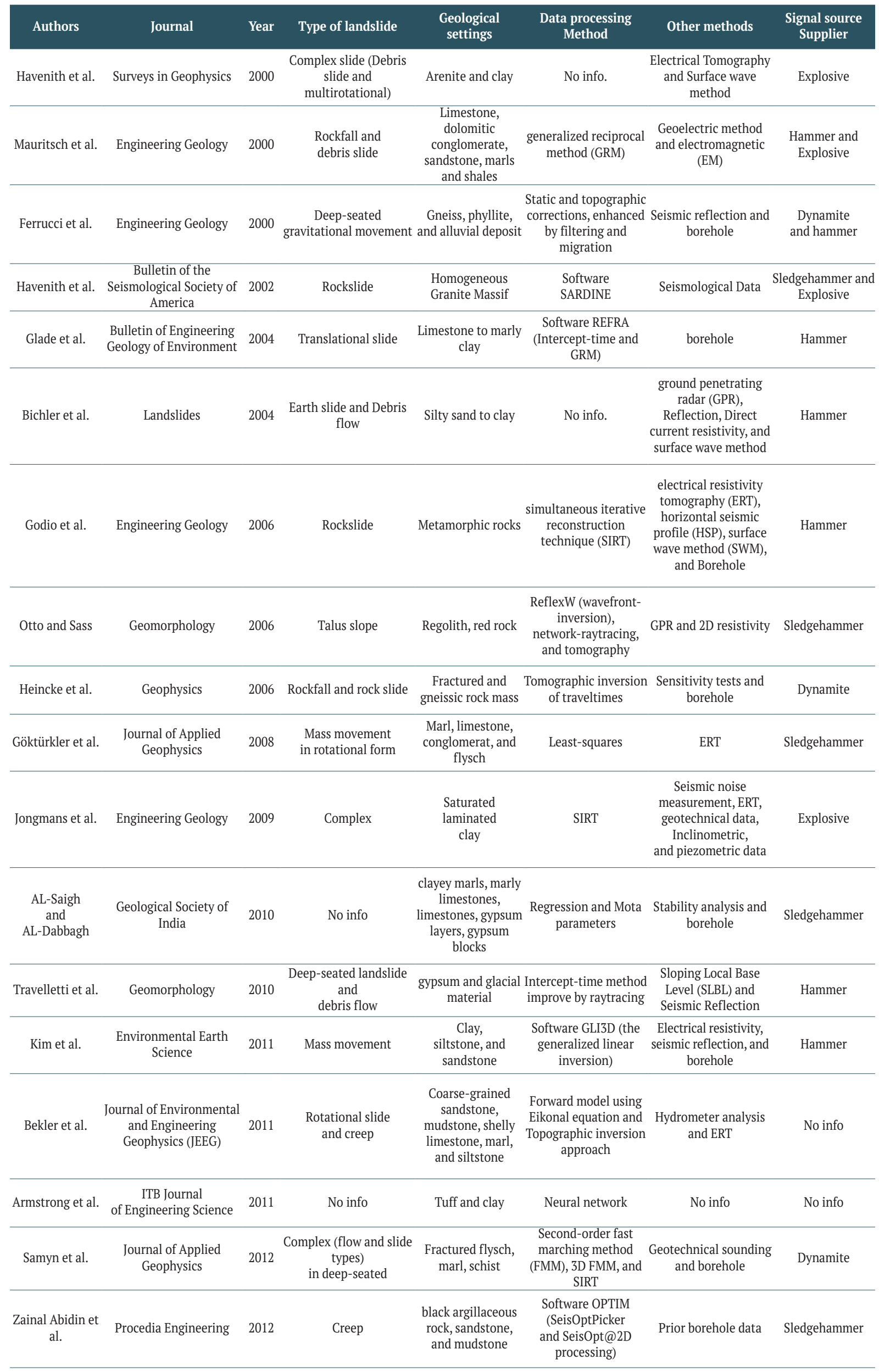




\section{Applications of SRT for landslide monitoring}

\begin{tabular}{|c|c|c|c|c|c|c|c|}
\hline Donohue et al. & $\begin{array}{c}\text { European Association of } \\
\text { Geoscientists \& } \\
\text { Engineers (EAGE) }\end{array}$ & 2012 & Quick-clay & $\begin{array}{l}\text { Clay and salt } \\
\text { content }\end{array}$ & $\begin{array}{l}\text { Software GREMIX } \\
\text { including plus-minus } \\
\text { method, GRM, and } \\
\text { slope-intercept }\end{array}$ & $\begin{array}{c}\text { EM conductivity } \\
\text { mapping, ERT, } \\
\text { Multichannel Analysis } \\
\text { of Surface Waves } \\
\text { (MASW), rotary } \\
\text { pressure sounding, } \\
\text { cone penetration tests } \\
\text { (CPT’s), and borehole }\end{array}$ & Sledgehammer \\
\hline Solberg et al. & $\begin{array}{l}\text { Bulletin of } \\
\text { EngineeringGeology of } \\
\text { Environment }\end{array}$ & 2012 & Quick-clay & $\begin{array}{l}\text { Clay, silt, sand, } \\
\text { active erosion, and } \\
\text { ice-marginal } \\
\text { deposit }\end{array}$ & No info & $\begin{array}{l}\text { Resistivity } \\
\text { measurement and } \\
\text { geotechnical } \\
\text { investigation }\end{array}$ & Dynamite \\
\hline Ozcep et al. & $\begin{array}{l}\text { Environmental Earth } \\
\text { Sciences }\end{array}$ & 2012 & Slope stability & $\begin{array}{l}\text { Silty clay, clayey } \\
\text { sand, } \\
\text { claystone, clay }\end{array}$ & $\begin{array}{l}\text { Software SeisImager } \\
\text { (time-term inversion) }\end{array}$ & $\begin{array}{l}\text { MASW, in-situ testing } \\
\text { (SPT), and borehole }\end{array}$ & No info. \\
\hline Capizzi et al. & $\begin{array}{c}\text { Journal of Geophysics and } \\
\text { Engineering }\end{array}$ & 2014 & Translational slide & $\begin{array}{l}\text { Calcarenites, silt, } \\
\text { sand, } \\
\text { and clay }\end{array}$ & $\begin{array}{c}\text { wave path eikonal } \\
\text { travel time (WET) } \\
\text { method, smooth } \\
\text { inversion }\end{array}$ & $\begin{array}{l}\text { ERT, Horizontal-to- } \\
\text { Vertical Spectral Ratio } \\
\text { (HVSR), and MASW }\end{array}$ & No info. \\
\hline Soon Min et al. & $\begin{array}{l}\text { Electronic Journal of } \\
\text { Geotechnical Engineering } \\
\text { (EJGE) }\end{array}$ & 2015 & Complex & $\begin{array}{l}\text { Weathered schist, } \\
\text { sandstone, and } \\
\text { shale }\end{array}$ & $\begin{array}{l}\text { Software SeisImager } \\
\text { (time-term inversion) }\end{array}$ & Borehole & Sledgehammer \\
\hline Grit and Kanli & Open Geoscience & 2016 & No info & $\begin{array}{l}\text { conglomeratesands } \\
\text { tone, } \\
\text { clay, limestone }\end{array}$ & $\begin{array}{l}\text { Raytracing technique } \\
\text { and SIRT }\end{array}$ & $\begin{array}{c}\text { Seismic reflection and } \\
\text { MASW }\end{array}$ & Sledgehammer \\
\hline Uhlemann et al. & $\begin{array}{l}\text { Journal of Applied } \\
\text { Geophysics }\end{array}$ & 2016 & $\begin{array}{l}\text { Earth slide and earth } \\
\text { flow }\end{array}$ & $\begin{array}{l}\text { grey to } \\
\text { dark-grey mudstone } \\
\text { and siltstone }\end{array}$ & $\begin{array}{l}\text { Inversion algorithm } \\
\text { using Elastic moduli } \\
\text { and Regularization }\end{array}$ & Borehole & Sledgehammer \\
\hline Wang et al. & Tectonophysics & 2016 & Quick-clay & Clay & $\begin{array}{l}\text { Raytracing algorithm } \\
\text { for sparse linear } \\
\text { equation and sparse } \\
\text { least-squares (LSQR), } \\
\text { and Regularization }\end{array}$ & $\begin{array}{l}\text { Radiomagnetotellu } \\
\text { ric (RMT), Seismic } \\
\text { reflection, and } \\
\text { borehole }\end{array}$ & $\begin{array}{l}\text { Weight-drop, } \\
\text { explosive, and } \\
\text { hammer }\end{array}$ \\
\hline Karsli et al. & $\begin{array}{c}\text { Eurasian Journal of Soil } \\
\text { Sciences }\end{array}$ & 2017 & $\begin{array}{c}\text { Historical } \\
\text { landslide and } \\
\text { lake sediments }\end{array}$ & $\begin{array}{l}\text { Basalt, } \\
\text { Gravely silty clay, } \\
\text { Clay }\end{array}$ & Tomographic method & $\begin{array}{c}\text { Refraction } \\
\text { Microtremor (ReMi), } \\
\text { MASW, Seismic } \\
\text { reflection, borehole, } \\
\text { and geotechnical } \\
\text { methods }\end{array}$ & Sledgehammer \\
\hline Jacob et al. & Engineering Geology & 2018 & Rockfall and flow & $\begin{array}{l}\text { Sand, clay, } \\
\text { and chalk cliff }\end{array}$ & WET & Gravity, borehole & $\begin{array}{l}\text { Weight-drop and } \\
\text { explosive }\end{array}$ \\
\hline $\begin{array}{l}\text { Kul Yahşi and } \\
\text { Ersoy }\end{array}$ & $\begin{array}{c}\text { Journal of Geophysics and } \\
\text { Engineering }\end{array}$ & 2018 & Slope stability & Clay, silt, and sand & No info. & $\begin{array}{l}\text { GPR, ERT, and } \\
\text { borehole }\end{array}$ & No info \\
\hline $\begin{array}{l}\text { Yilmaz and } \\
\text { Kamaci }\end{array}$ & $\begin{array}{l}\text { International Journal of } \\
\text { Computational and } \\
\text { Experimental Science } \\
\text { and Engineering }\end{array}$ & 2018 & Slope stability & Clay & No info. & $\begin{array}{l}\text { Vertical electrical } \\
\text { sounding (VES) }\end{array}$ & No info. \\
\hline Mezerreg et al. & $\begin{array}{l}\text { Journal of African Earth } \\
\text { Sciences }\end{array}$ & 2019 & Creep & $\begin{array}{l}\text { Matrix of sand-clay, } \\
\text { Sandstone pebbles } \\
\text { and Limestone } \\
\text { debris }\end{array}$ & $\begin{array}{c}\text { Software } \\
\text { Reflex W (wavefront- } \\
\text { inversion) }\end{array}$ & $\begin{array}{l}\text { ERT, borehole, and } \\
\text { geotechnical methods }\end{array}$ & Hammer \\
\hline $\begin{array}{l}\text { Nwankwo and } \\
\text { Ugbena }\end{array}$ & World Scientific News & 2019 & No info. & $\begin{array}{l}\text { Sandstone, } \\
\text { conglomerate, } \\
\text { shale, grey } \\
\text { mudstone }\end{array}$ & $\begin{array}{c}\text { Software Reflex W } \\
\text { (wavefront-inversion) }\end{array}$ & VES, ERT & Hammer \\
\hline Chen et al. & $\begin{array}{c}\text { Journal of Environmental } \\
\text { and Engineering } \\
\text { Geophysics }\end{array}$ & 2019 & Rockfall & $\begin{array}{l}\text { Silty clay, } \\
\text { mudstone, } \\
\text { sandstone }\end{array}$ & LSQR & $\begin{array}{l}\text { ERT, Scattered wave } \\
\text { imaging (SSI), and } \\
\text { borehole }\end{array}$ & Hammer \\
\hline
\end{tabular}

Table 1. Studies using conventional seismic refraction and seismic refraction tomography methods in landslide investigations and published in valid journals since 2000. 


\section{Parisa Imani et al.}

\subsection{Data acquisition}

The SRT survey design for characterizing landslides must be adjusted when applied in different studies. After a careful reconnaissance of the topographic conditions, landslide type, hydrogeological and lithological characteristics of the study area, landslide extent, and objective depth, a survey strategy should be carefully designed to cover stable and unstable terrains. In other words, generally, seismic refraction lines should be positioned over landslide scars and beyond that to compare the subsurface images. The profiles are typically extended closest to the borehole location drilled into a catastrophic region [Abraham and Lucius, 2004]. The profile length depends on the constraint of the landslide site extension and should be approximately three to five times the investigation depth.

The number of seismic profiles depends on the size of the investigation area. For better illustration of the underground in landslide studies, it is necessary to spread out at least three longitudinal lines (along with the sliding direction) and several traverse profiles positioned over the failure surface and beyond that [Bogoslovsky and Ogilvy, 1977].

The in-field procedure is conducted with three main seismic equipment elements, including a seismic source and several seismic receivers connected to the seismograph through cables. The geophones (receivers) connected to the seismograph through cables receive the signals generated by sources. The detectors are applied for travel time measurement. Knowing the values of time and depth, the apparent velocity values characterizing the subsurface studied can be computed. The calculated values and inverted velocities are placed at their positions to represent the subsoil velocity images.

The geophones and sources are deployed on a linear strategy system in refraction surveys and usually placed along a single line. This means that the SRT is generally carried out along a line of geophones with end- and offend sources at each end of the profiles (Figure 1).

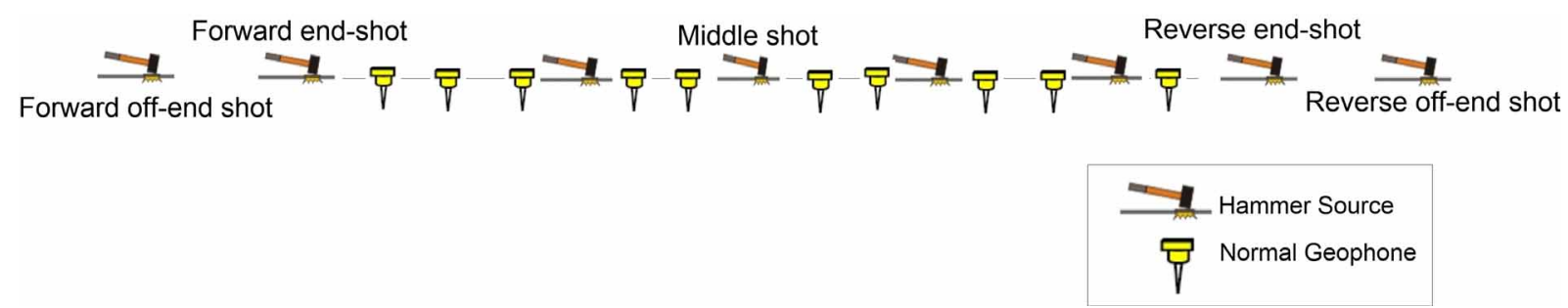

Figure 1. Schematic image of typical 2D seismic refraction survey strategy.

Additionally, for the in-field procedure, the travel time quality control (QC) of seismic refraction data is essential due to the expensive and time-consuming fieldwork. According to seismic imaging, shorter travel times are related to the geophones placed near sources, and longer travel times are related to the receivers placed far away from sources [Göktürkler et al., 2008]. Imani [2020] and Adamczyk et al. [2013] controlled the quality of travel times by blowing at the shot point at a distance of $0 \mathrm{~m}$ during acquiring data. As shown in Figure 2, according to the seismic traces, shorter travel times belong to receivers located near the sources, and longer travel times come from far sources.

The resolution of images obtained by refraction survey is influenced by the receiver spacing, signal source frequency, and the shot number [Hack, 2000]. The geophone spacing and frequency should be based on an on-site extension and soil heterogeneity, respectively [Armstrong et al., 2011]. The frequency of the geophones should be adequate to sliding objectives. Typically, in shallow seismic investigations, particularly landslide studies, the natural frequency used is $4.5 \mathrm{~Hz}$ [Capizzi and Martorana, 2014; Glade et al., 2005; Havenith et al., 2002; Havenith et al., 2000; Imani, 2020; Imani and Tian, 2018; Imani et al., 2021b; Jongmans et al., 2009; Karslı et al., 2017; Kim et al., 2011; Uhlemann et al., 2016; Vanlı Senkaya et al., 2019]. However, geophones with higher frequencies (10, 14, and $28 \mathrm{~Hz})$ are likely applied in sliding studies [Adamczyk et al., 2013; Bekler et al., 2011; Donohue et al., 2012; Glade et al., 2005; Godio et al., 2006; Grit and Kanli, 2016; Jacob et al., 2018; Mezerreg et al., 2019; Ng et al., 2015; Travelletti et al., 2010; Wang et al., 2016; Zainal Abidin et al., 2012]. Since the reliability of the refraction results depends on the accuracy of the picking first break, the first onsets should be recognizable. Lower frequency geophones are more 
sensitive to arrival signals, even including noises of higher frequency, and require data with more unwanted noises. At the same time, this can present geological structures with more details. Therefore, locating the onset of the arrivals acquired from landslide sites with heterogeneous surfaces can be troublesome and requires great attention while picking. However, no case of inefficiency of various geophone frequencies has been reported in this paper.

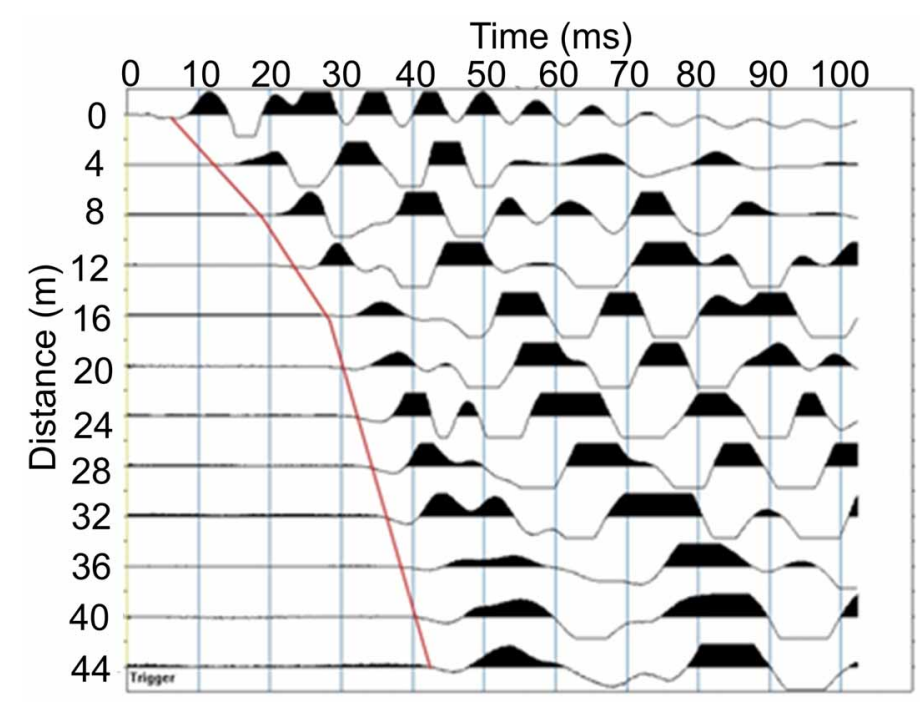

Figure 2. Seismic travel times are created by a shot blown on a few centimeters from a distance of zero. The solid red line shows the picked first arrivals [Imani, 2020].

Seismic signals are generated by various sources, such as explosives, hammers, weight-drops, and vibroseis. Impulsive sources are selected based on the geological conditions, efficiency, accessibility, cost-effectiveness, safety, generation of more energy, and reproducibility. The anomaly depth, the required resolution, good quality data, and environmental friendliness are also factors considered while choosing the signal source [Malehmir et al., 2013b]. For years, the sledgehammer blown on a metal plate was known as the low-frequency seismic signal source in geophysical projects and was much safer than other sources to use in early-trigger landslide regions. One more benefit of using a sledgehammer is to create a high-resolution image of subsoil heterogeneities [Havenith et al., 2002]. Since most landslide sites are investigated on the facing after the events, the heterogeneity of the failure surface causes more seismic signal attenuation and leads to a low penetration depth [Imani et al., 2021a; Imani et al., 2021b]. Therefore, a heavy hammer should be considered to generate energetic signals with high penetration depths [Imani, 2020]. Figures 3a and $3 \mathrm{~b}$ show the various data quality of the two raw travel times triggered by $5 \mathrm{~kg}$ and $9 \mathrm{~kg}$, respectively. In this study, energetic signals have been generated by a heavy hammer with the same geological conditions, operator's skill, and strength.

If the sledgehammer as a seismic source cannot supply enough energy into the earth, it is suggested to switch the signal source to explosives or weight-drops [Mauritsch et al., 2000]. They are more expensive and dangerous and require more safety precautions while using in landslide sites [Rashed, 2009]. Malehmir et al. [2013a] and Jacob et al. [2018] introduced weight-drops and dynamite as good sources with high-frequency content and energy for quickclay data analysis. They proved that the explosives have enough potential to map deep bedrock, the reflected waves, and wide-angle reflections. In very shallow depths, dynamite loads can provide a dominant frequency of $45 \mathrm{~Hz}$ in the recorded range from 25 to $200 \mathrm{~Hz}$, providing sufficient energy into the subsoil [Samyn et al., 2012]. However, due to the sensitivity and instability of landslide sites, it is recommended to employ deep shots to prevent further destruction caused by triggering landslides [Heincke, 2005].

Based on Table 1, most of the studies (53\%) on landslide regions with different rock characterizations used a sledgehammer to supply the signal source [Al-Saigh and Al-Dabbagh 2010; Glade et al., 2005; Godio et al., 2006; Göktürkler et al., 2008; Havenith et al, 2002; Kim et al., 2011; Mauritsch et al., 2000; Travelletti et al., 2010; Zainal 


\section{Parisa Imani et al.}

Abidin et al. 2012 ; Donohue et al., 2012; Hibert et al., 2012; Ng et al., 2015; Imani, 2020]; Imani and Tian, 2018; Imani et al., 2021b; Karslı et al., 2017; Mezerreg et al., 2019; Uhlemann et [2016; Wang et al. 2016], a lower percentage (15\%) applied explosives [Havenith et al., 2000; Heincke et al., 2010; Jongmans et al., 2009; Samyn et al., 2012; Solberg et al., 2012]; 15\% considered the combined sources, i.e., explosives, handy hammer and weightdrop [Ferrucci et al., 2000; Havenith et al., 2002; Jacob et al., 2018; Mauritsch et al., 2000; Wang et al., 2016]; and there is no information regarding a signal supplier for 17\% (Figure 4) [Bekler et al., 2011; Capizzi and Martorana, 2014; Kul Yahşi and Ersoy, 2018; Ozcep et al., 2012; Sompotan et al., 2013; Yilmaz and Kamaci, 2018].

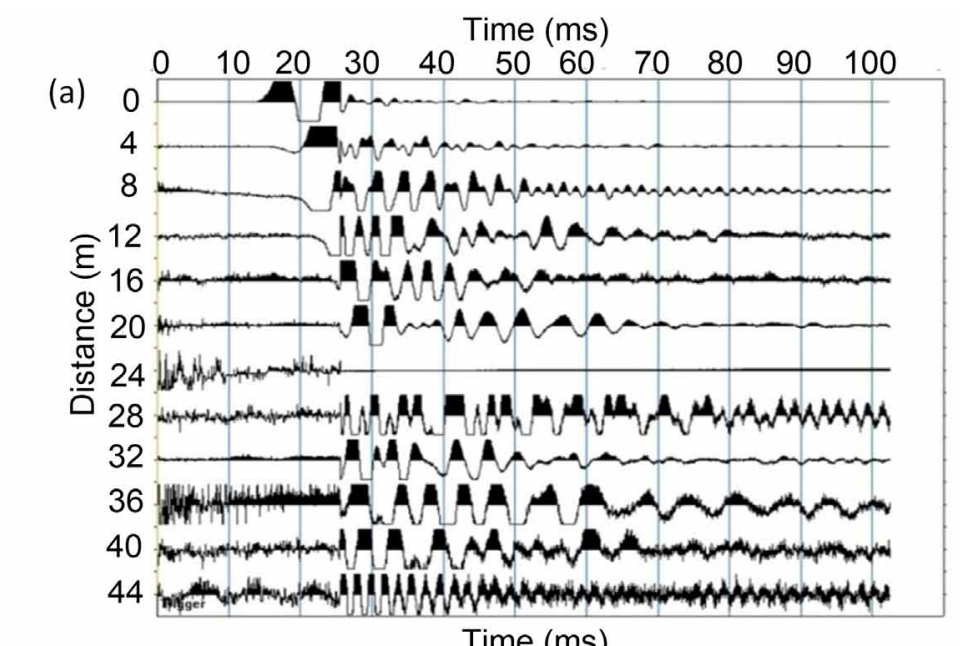

(b)

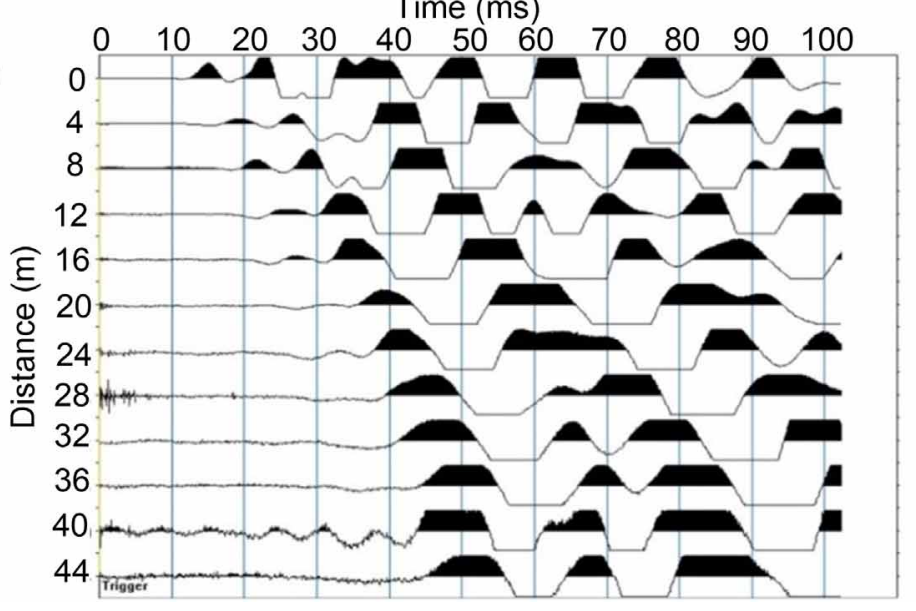

Figure 3. Seismic traces were obtained from different signal sources along with the seismic profile [Imani, 2020]. (a) A 5 kg sledgehammer triggers the signals. (b) A 9 kg sledgehammer triggers the signals.

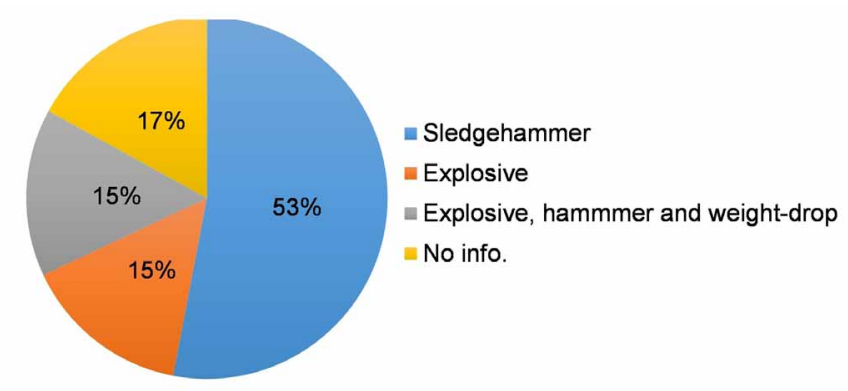

Figure 4. Percentage proportions in the types of sources presented in the review. The pie graph illustrates that most studies considered have applied the sledgehammer as the single source in landslide study. 
Figure 5 shows the comparison among the power spectra for a sledgehammer, weight-drop, and dynamite. The weight-drop sources have intermediate frequency content with broader bandwidth spectra, better resolution, and higher amplitude than the sledgehammer and dynamite [Malehmir et al., 2013a]. Dynamite provided the highest frequency with the best signal-to-noise $(\mathrm{S} / \mathrm{N})$ ratio compared with the other sources [Malehmir et al., 2013a]. The weakest signals belong to the sledgehammer.

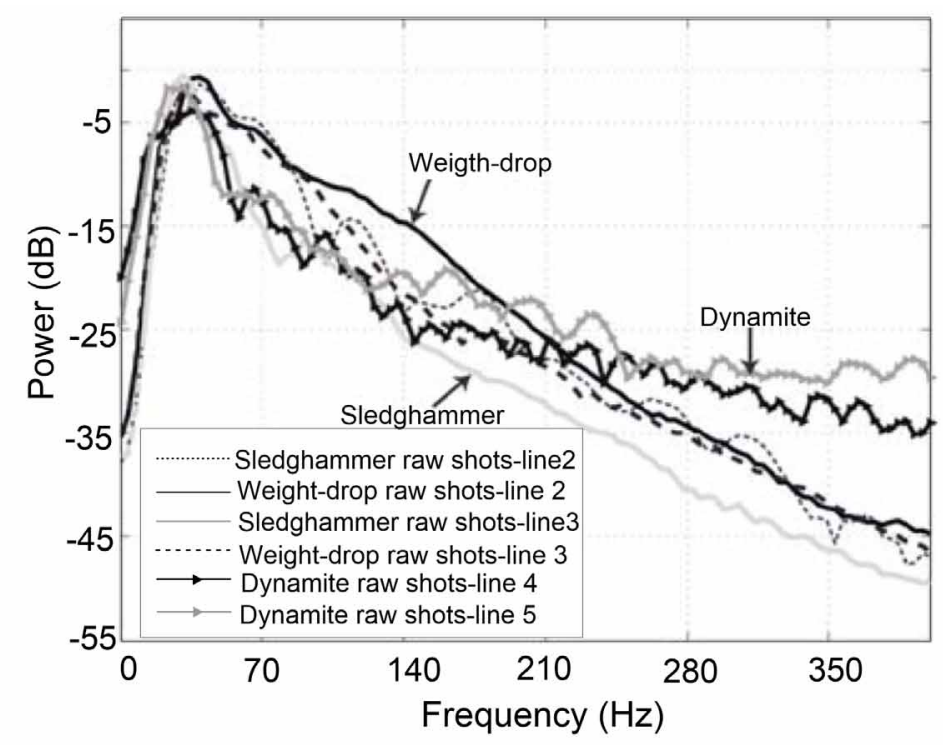

Figure 5. Comparisons of power spectra with dynamite, sledgehammer, and weight-drop as the signal sources [Malehmir et al., 2013a].

Comparing the weight-drop, shotgun, and hammer in saturated and fine-grained materials proved that the shotgun could produce a higher frequency signal than the weight-drop could (Figure 6) [Pullan and MacAulay, 1987].

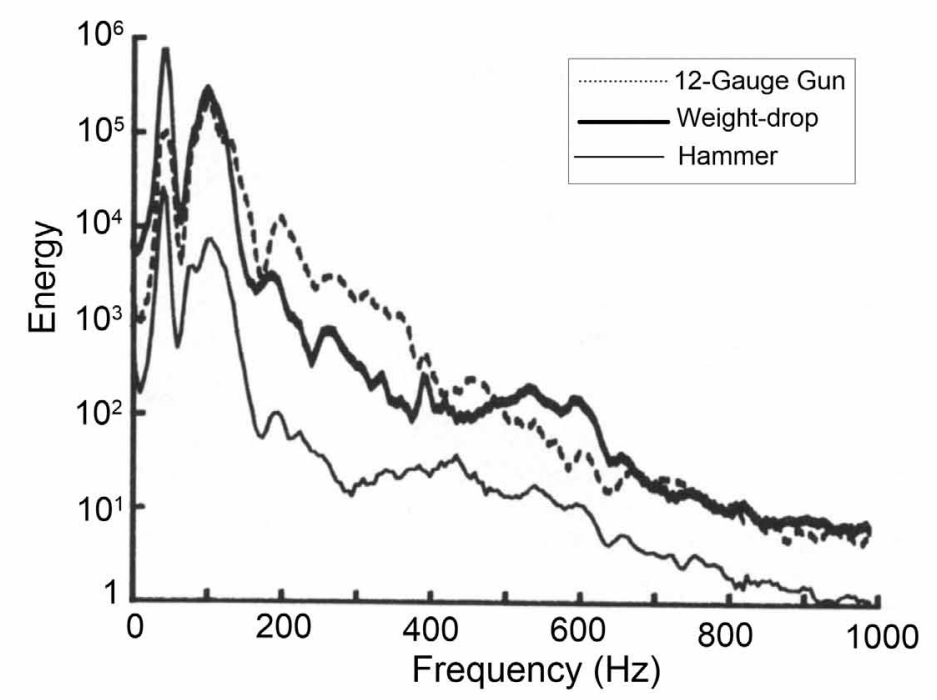

Figure 6. The plotted power spectra from the hammer, weight-drop, and shotgun as signal sources [Pullan and MacAulay, 1987]. 


\section{Parisa Imani et al.}

The number of shot points and their positions are the other parameters considered to provide high-resolution results. The multiple shot-points along with the survey line can produce more accurate data [Donohue et al., 2012; Jacob et al., 2018; Mezerreg et al., 2019; Narwold and Owen, 2002], better-layered velocity models, and interface depth estimation [Rucker, 2000]. Samyn et al. [2012] designated five profiles of sources perpendicular to the sliding direction and four geophone lines in the sliding direction in rugged topography and complex (flow and slide type) landslide studies using 3D SRT (Figure 7). This survey layout, including several source lines, can provide homogeneous illumination and high 3D coverage of the subsurface.

Furthermore, data stacking of shots can significantly improve the resolution of images. To reach this goal, each shot point should be repeatedly stacked to increase the signal to noise ratio $(\mathrm{S} / \mathrm{N})$ and signal improvement [AlSaigh and Al-Dabbagh, 2010; Al-Saigh, 2010; Bekler et al., 2011; Capizzi and Martorana, 2014; Göktürkler et al., 2008; Imani, 2020; Karslı et al., 2017; Kim et al., 2011; Malehmir et al., 2013a; Otto and Sass, 2006; Uhlemann et al., 2016]. As there is a frequent problem in landslide investigation and its soil conditions, and that is the incompact soil observed in post-event areas, which can prevent seismic wave penetration to greater depths due to wave attenuation and signal scattering [Bruno and Martillier, 2000], it is strongly suggested to significantly increase the $\mathrm{S} / \mathrm{N}$ ratio and to carefully choose the acquisition parameters and signal sources [Bruno and Martillier, 2000].

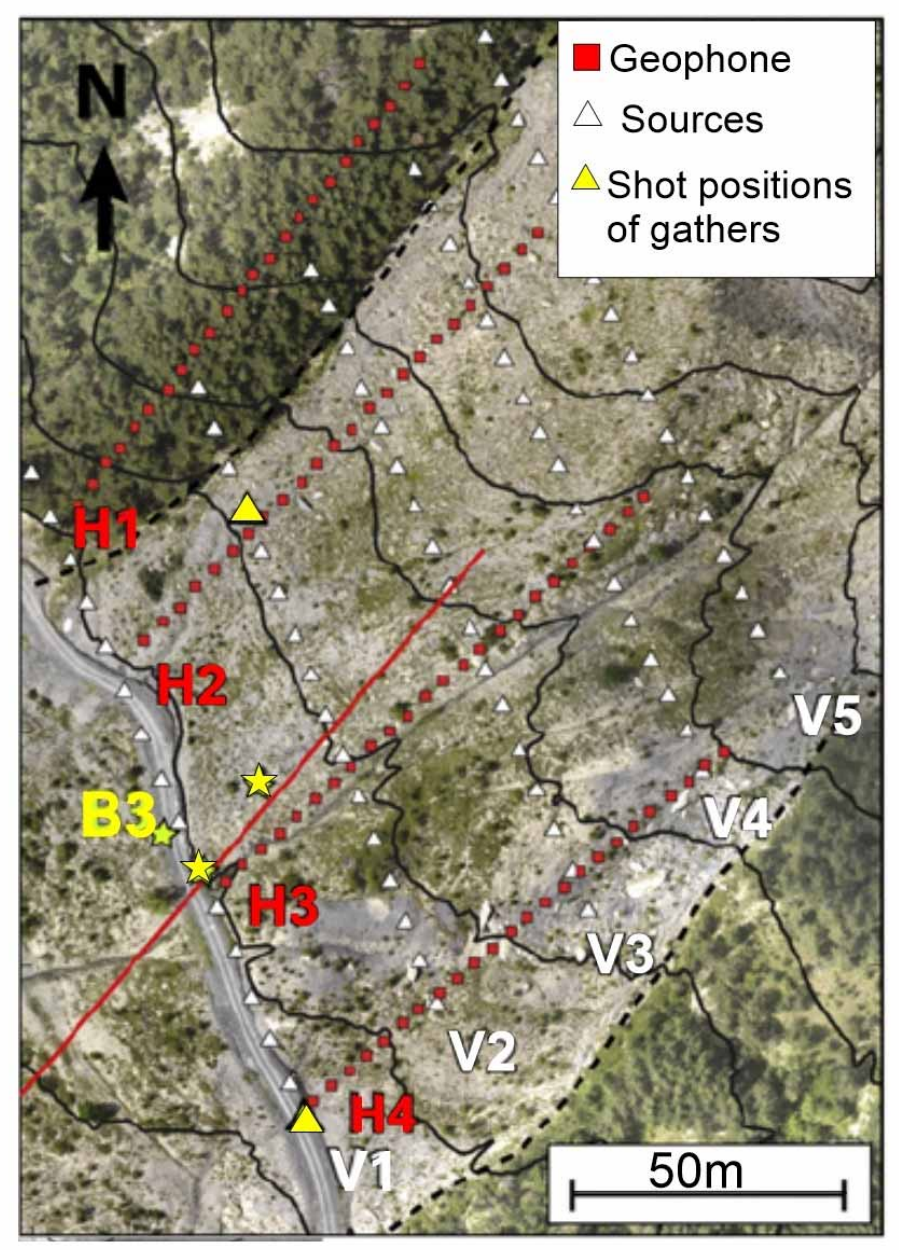

Figure 7. Presentation of the study area orthophotograph overlapped by the seismic refraction tomography (SRT) survey strategy, including the receiver and source lines [Samyn et al., 2012].

The overlapped refraction survey method can also cover the gaps between shots and prevent missing data while acquiring the data [Glade et al., 2005]. Figure 8 depicts a survey layout by Bekler et al. [2011]. The overlapping degree is at six receivers, each of them planted at every shot point, with one reverse and one forward off-end shot. 


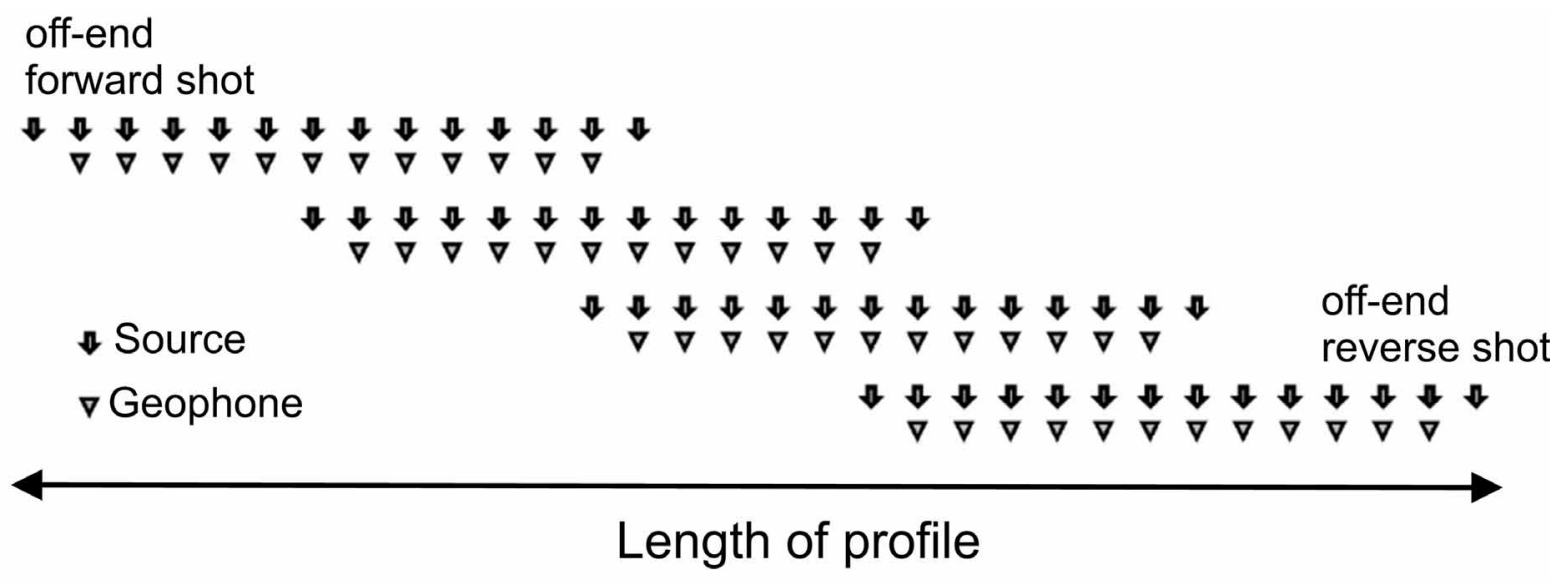

Figure 8. A schematic of the overlapped survey strategy of the SRT method [Bekler et al., 2011].

The Laser-Tachymeter system is rarely applied for the accurate determination of receiver spreads, shot point layout, topographic conditions, and the surface of the ground along with the seismic lines in landslide investigations [Glade et al., 2005]. Significantly, in landslide monitoring projects, this system helps to investigate changes in the surface elevation, considers seismic profile alignments, and locates the geophone and shot points.

The survey design explained above should be considered in 2D or 3D illustrations to show the complicated structure of landslide sites. These imaging methods make the subsoil images more attractive and informative for landslide investigations. Although the relationship between the geophysical properties and geotechnical and geological parameters is still considerable, the 2D and 3D imaging procedures play a brilliant role in monitoring and characterizing landslides. These techniques are interested in depicting and evaluating the landslide geometry, the physical properties of sliding mass, the water table location, and interflow direction. The 2D and 3D images appeared through a strategy survey and inversion process [Bogoslovsky and Ogilvy, 1977]. Despite the three-dimensional nature of landslides, there are very few studies that applied the 3D SRT survey [Heincke et al., 2010] in landslide studies, while the 2D SRT survey is more attractive to use in characterizing rotational/translational slide types [Armstrong et al., 2011; Capizzi and Martorana, 2014; Göktürkler et al., 2008; Grit and Kanli, 2016], flow and slide typology [Samyn et al., 2012; Travelletti et al., 2010], creep [Zainal Abidin et al., 2012], complex [Jongmans et al., 2009], rockslide [Havenith et al., 2002], unstable slope [Otto and Sass, 2006], debris flow, and soil slide [Imani and Tian, 2018; Imani et al., 2021b].

As landslide structures are 3D phenomena and the obtained images are 2D, the illustrations may be influenced by strong artifacts that can be difficult to identify. Therefore, 2D and 3D forward modeling can solve this problem and easily assess image reliability [Jongmans and Garambois, 2007]. Those studies performed using 3D seismic surveys illustrate the 3D geological structure of landslides and delineate the landslide geometry [Samyn et al., 2012; Uhlemann et al., 2016]. Samyn et al. [2012] recommended surveying the complex structure and process data in 3D imaging. Figure 9 shows the seismic velocity distribution in flow and slide types in a deep-seated landslide with lowto high-velocity values and distinguishes the morphological features within the landslide [Samyn et al., 2012]. This $3 \mathrm{D}$ velocity model provided good agreement with the 2D SRT section. Therefore, the obtained results can define the reliability of the $2 \mathrm{D}$ model as well as the $3 \mathrm{D}$.

After survey strategy design, the type of seismic wave should be considered in sliding studies. It can be P-waves (primary or compression wave) or S-waves (secondary or shear wave). Various properties of landslide materials can affect the behavior of different types of waves. P-waves are typically determined in landslide investigations because they are easily generated and have more sensitivity to the material's normal stiffness changes. At the same time, S-waves are affected by the material shear stiffness [Hack, 2000]. P-waves and S-waves simultaneously present lower values in landslide materials, particularly after sliding (e.g., deep-seated creep based on Mauritsch et al. [2000] and higher values in landslide bedrock [Bichler et al., 2004; Jongmans et al., 2009; Uhlemann et al., 2016]. In most studies carried out in landslide areas using SRT, the first break collected included P-wave data [Armstrong et al., 2011; Bekler et al., 2011; Capizzi and Martorana, 2014; Donohue et al., 2012; Ferrucci et al., 2000; Göktürkler et al., 


\section{Parisa Imani et al.}

2008; Grit and Kanli, 2016; Havenith et al., 2002; Havenith et al., 2000; Heincke, 2005; Imani, 2020; Imani and Tian, 2018; Jacob et al., 2018; Karslı et al., 2017; Mezerreg et al., 2019; Nwankwo and Ugbena, 2019; Ostrowski and Lasocki, 2018; Otto and Sass, 2006; Samyn et al., 2012; Travelletti et al., 2010; Vanlı Senkaya et al., 2019; Zainal Abidin et al., 2012]; however, some literature supplemented the landslide studies using S-wave refractions [Bichler et al., 2004; Jongmans et al., 2009; Ozcep et al., 2012; Uhlemann et al., 2016; Yilmaz and Kamaci, 2018].

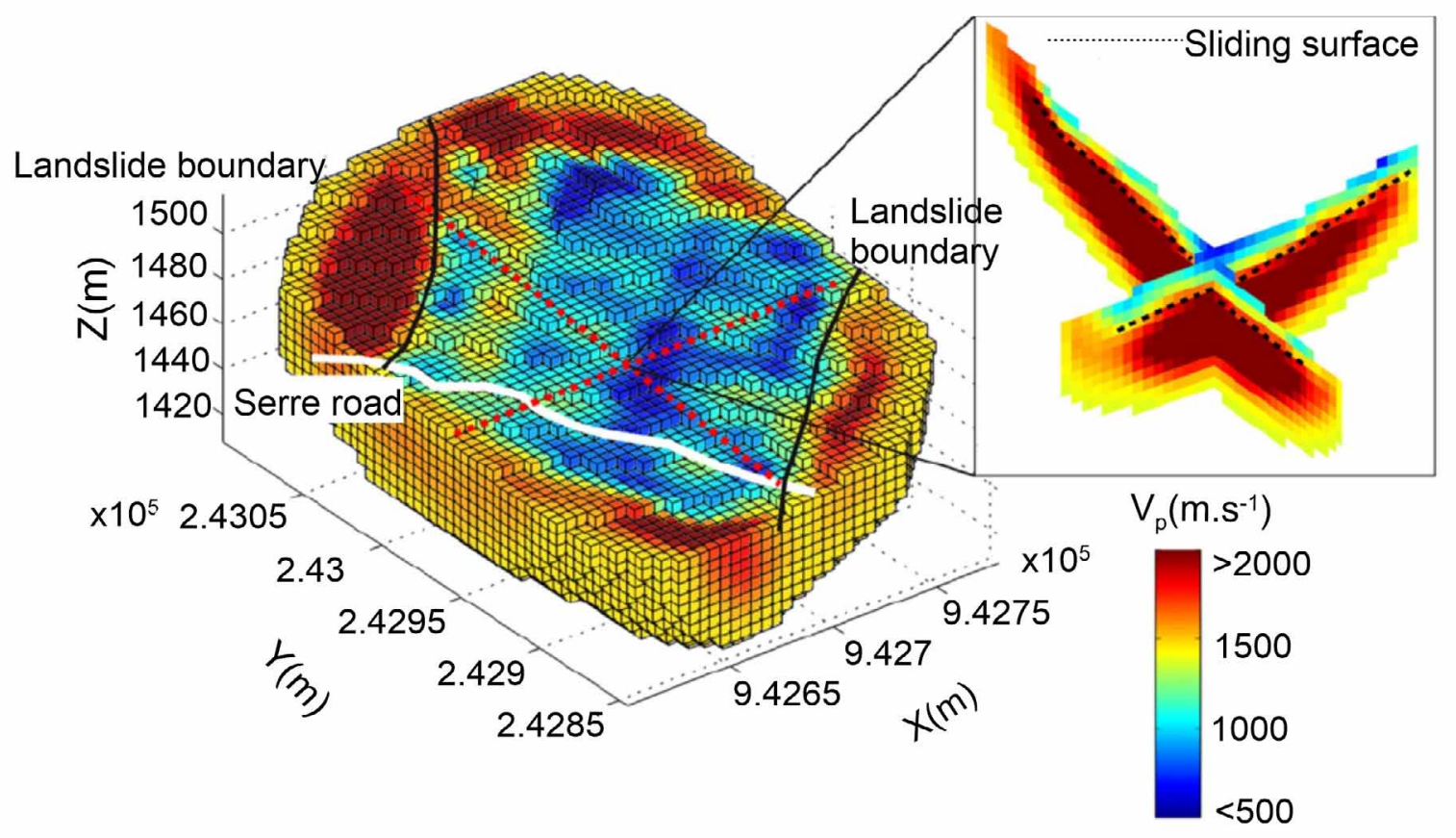

Figure 9. 3D seismic tomogram at the La Valette applied on a complex landslide to outline the boundary between the landslide and the surrounding stable slopes [Samyn et al., 2012].

As P-wave velocity (Vp) is controlled by the water content and saturated clay, and slightly influenced by gravitational deformation [Godio et al., 2006], the S-wave velocity (Vs) can characterize the landslide structure and its activity, material porosity, and compaction [Grandjean and Sage, 2004]. The most sensitive variant to deformation is caused by the saturated clay contents [Jongmans et al., 2009]. To characterize the quick-clay landslides and determine the elastic constants, integration of the P- and S-wave velocity models can obtain more reliable results and helpful information on the hazard analysis [Adamczyk et al., 2013]. In quick-clay zones with high risk, it is often suggested to investigate beyond the considered zone to evaluate the sand stability [Solberg et al., 2012].

Uhlemann et al. [2016] collected the Vp and Vs to characterize earth slide and earth flow in the UK. In this study, the wave velocities were too low to image the lithological structures at the site. Still, subsoil imaging was improved with the Poisson's ratio from the velocity distributions. The advantage of collecting Vp and Vs is to show a substantial disparity created by the water table absence in low precipitation seasons or areas [Capizzi and Martorana, 2014]. Despite the benefits of determining P- and S-wave velocities simultaneously, it is probable that the resulting images may not be high resolution in high-slope cases (30-40 degrees) where operators confront the difficulties of data acquisition and coupling on the surface [Bichler et al., 2004].

However, when additional wave types are analyzed, supplementary information about the mechanical properties of the near-surface geological materials becomes available, although at the cost of invoking more complicated procedures [Bichler et al., 2004]. 


\section{Applications of SRT for landslide monitoring}

\section{Data processing and interpretation}

The processing and interpretation of seismic refraction data involve the models of primary or secondary wave velocities based on inverse or forward modeling of the obtained travel times. Over the last decades, the inversion method as a more efficient and faster modeling tool mainly replaced the forward technique for characterizing landslide areas. Compared to the inversion procedure, the forward modeling technique attempts to fit the obtained data from several source locations simultaneously through trial and error. The manual process is a challenging, tiring, time-consuming method. The modification sequence of forward modeling defines subjectivity into the final model and depends on the interpreter's skill and experience.

The inversion results also depend on the accuracy of picking first breaks, the choice of processing settings, the parameters set only once, and the computations are easily iterated. However, forward modeling was able to identify the reliability of the obtained illustrations as the most crucial advantage of this modeling method. Since landslide bodies have complicated settings, seismic inversion models can develop the map of subsoil velocity contrasts with a higher resolution and as less time consuming than forward modeling [Bekler et al., 2011]. There was only one study found that identified the landslide characteristics. Bekler et al. [2011] employed forward, and inverse modelings to access reliable travel time using a finite-difference solution of the Eikonal equation in the rotational slide and creep types. This combination can produce a very accurate subsurface model composed of the saturated clay-rich and sand-rich zones.

The studies that used inversion techniques are collected in Table 1. The inversion of seismic data can be a reliable and standard way to estimate landslide characteristics [Nolet, 1987]. A primary model, an inversion problem solver to determine travel times and ray paths, a proper algorithm, and control of the tomogram quality are the essential inversion steps [Heincke et al., 2006]. The combination of inversion methods and geological/geotechnical information can also clarify the subsurface structures' ambiguities. Also, the stratigraphic information obtained from geological/geotechnical methods, such as boreholes, can calibrate the inversion results and image resolutions [Capizzi and Martorana, 2014].

For the processing of seismic data, selecting the correct processing sequence and proper variants, assessing the results, and determining deficiencies by choosing the inappropriate parameters are the three essential steps [Yilmaz, 1987]. The SRT data gives reliable results in landslide investigations after considering these points. Since the objective of every seismic method is to achieve the subsurface image, the recorded data should be converted to sections processed by different algorithms. The seismic sections aim to detect the lateral and vertical velocity changes, the up and down slopes, the discontinuous refractors, and the diffracted blocks through the landslide mass [Narwold and Owen, 2002]. However, the variety of subsurface sediments and sliding material properties influence the seismic velocities illustrating different horizons [Abramson et al., 2002].

In this part of the paper, we attempt to collect the seismic refraction processing methods that have been used to identify landslide characterizations. Since 1975, computer processing algorithms for seismic refraction data have been developed by the Geological Survey of New South Wales [Hatherly, 1980] and surpassed the manual methods. The primary step of seismic refraction data processing is to pick the first breaks of travel times generated by the shots in-field procedure and organize the data to obtain reliable results [Göktürkler et al., 2008; Telford. W. M. et al., 1990]. The following methods are the well-known processing procedures of seismic refraction data [Rubin and Hubbard, 2005]:

1. Conventional Reciprocal Method (CRM) [Edge and Laby, 1931; Hawkins, 1961],

2. Generalized Reciprocal Method (GRM) [Palmer, 1980; Palmer, 1981],

3. Intercept-Time Method (ITM) [Lankston, 1989; Palmer, 1981],

4. Delay-Time Method (DTM) [Bruckshaw, 1941],

5. Plus-Minus Method [Hagedoorn, 1959], similar to CRM, and

6. Refraction Tomography (RT).

The CRM is the most commonly used processing method for seismic refraction data in landslide investigations. This technique was developed in the 1930s when it was posed as the technique of disparities [Edge and Laby, 1931]. The CRM is differently named in various parts of the world, including Hagiwara's technique in Japan [Hagiwara, 1939; Kisunezaki, 1965], the reciprocal method in Australia [Hawkins, 1961], the plus-minus procedure in Europe [Hagedoorn, 1962], and the ABC method in the USA [Bruckshaw, 1941; Wilson, 1983]. The mentioned techniques are 


\section{Parisa Imani et al.}

mathematically and conceptually identical. The CRM is convenient to use and mostly applied in landslide studies with simple structures, plane boundaries, and invariant velocity in each layer. Most of the calculations are simple mathematical operations that can be performed with spreadsheets.

In the landslide sites, including the uniform seismic velocities and the subsurface horizons inclined less than $20^{\circ}$, the Intercept-Time and CRM Methods can professionally map the subsoil velocity structures [Narwold and Owen, 2002]. These two methods can model the layers and the refracted continuous interfaces across a profile. However, they cannot map the ray path velocity and interface irregularity on complex landslide structures [Narwold and Owen, 2002]. Travelletti et al. [2010] applied the intercept time method (ITM) to model the 2D velocity map then enhanced this by using the raytracing model on gypsum formations that affected the landslide phenomenon. As the landslide regions illustrate the complex velocity of the materials that rapidly change in the vertical and horizontal directions [Kul Yahşi and Ersoy, 2018], a few researchers recommend to analyze the seismic wave using software based on raytracing analysis [Bárta et al., 2005; Otto and Sass, 2006].

The refractor depths of each receiver point are estimated with the GRM method if the forward and reverse shots overlapping refraction arrival times are carried out when acquiring data [Mauritsch et al., 2000; Narwold and Owen, 2002]. The advantage of using the General Reciprocal Method (GRM) is to image the seismic refraction velocities consistently along with the profile. It does not depend on the variety of subsurface material properties [Mauritsch et al., 2000]. Some studies attempted to present the results obtained by GRM compared to the other refraction data processing methods [Glade et al., 2005; Lankston, 1989; Mauritsch et al., 2000; Narwold and Owen, 2002; Palmer, 1980]. The compared conclusions can help researchers to have a better understanding of the expected results.

In comparison between GRM and ITM, GRM significantly improves the seismic refraction technique utility. Despite ITM, it can particularly delineate the undulating refractors and determine lateral velocity changes in the horizons. However, the GRM and ITM can provide identical results when the layers and interfaces are planar and homogeneous [Palmer, 1980]. The ambiguities in seismic model interpretations typically developed in ITM are removed if the survey layout is designated with sufficient receivers and multiple shot points at both ends of the survey lines [Lankston, 1989]. Glade et al. [2005] employed the GRM method for determining the failure surface of a very shallow landslide (1 to $3 \mathrm{~m}$ depth), mapping the complex interface between the colluviums and marly and calcareous sediments.

The results show the shear plane on the boundary between well-contrasted layers, such as marls, clays, and colluviums. Then, the results were finally modified using drillings. Compared to Glade et al. [2005], Mauritsch et al. [2000] used the GRM processing method on the seismic refraction data of the large and deep landslide made of limestone, dolomitic conglomerates, sandstones, and shales with irregular and heterogeneous refractors (Figure 10). Therefore, this proved that the GRM produced seismic sections with good quality in shallow and deep landslides. In addition, the GRM method was successful in determining the internal landslide materials but unsuccessful in presenting the slip surface images.

The other processing method mentioned above is the delay-time method (similar to CRM and plus-minus). The delay-time method is one of the refraction data processing methods to calculate the depth and time beneath each geophone. This method can calculate the difference between the time spending by signals propagating on undulating or dipping refractor through the upper layer and the time that it could have spent traveling along with the normal refractor. In this technique, the true velocity can be computed by recording signals from two ends of the line (forward and reverse shots) [Musgrave, 1967]. It leads to the actual depth beneath the recorders with more details [Redpath, 1973]. Before using the delay-time method, it is compulsory to consider that the technique can be employed in the cases with an overlap zone between refracted signals coming from the same layer, as shown in Figure 11.

In this paper, only two studies were found to process the obtained seismic refraction data using the delay-time method. Imani et al. [2021b] calibrated the seismic inversion models obtained from the debris flow and soil slide site by the results obtained from the delay-time method. In this study, apart from the commercial software ZondST2D [Kaminskiy, 2013] applied for processing refraction data with the refraction tomography (RT) method (the leastsquares using the time-term inversion technique [Kaminskiy, 2013], the refraction data was manually processed using the delay-time technique to determine the velocity and depth beneath each geophone and synthesize the cross-section of the seismic profile. The geological cross-section of a profile was plotted in Figure 12a. The excellent agreement between the inversion model and the synthesized model proved the ability of the delay-time method to illustrate the refractor shapes and layer thicknesses and confirmed the reliability of the inversion model shown in Figure 12b. 

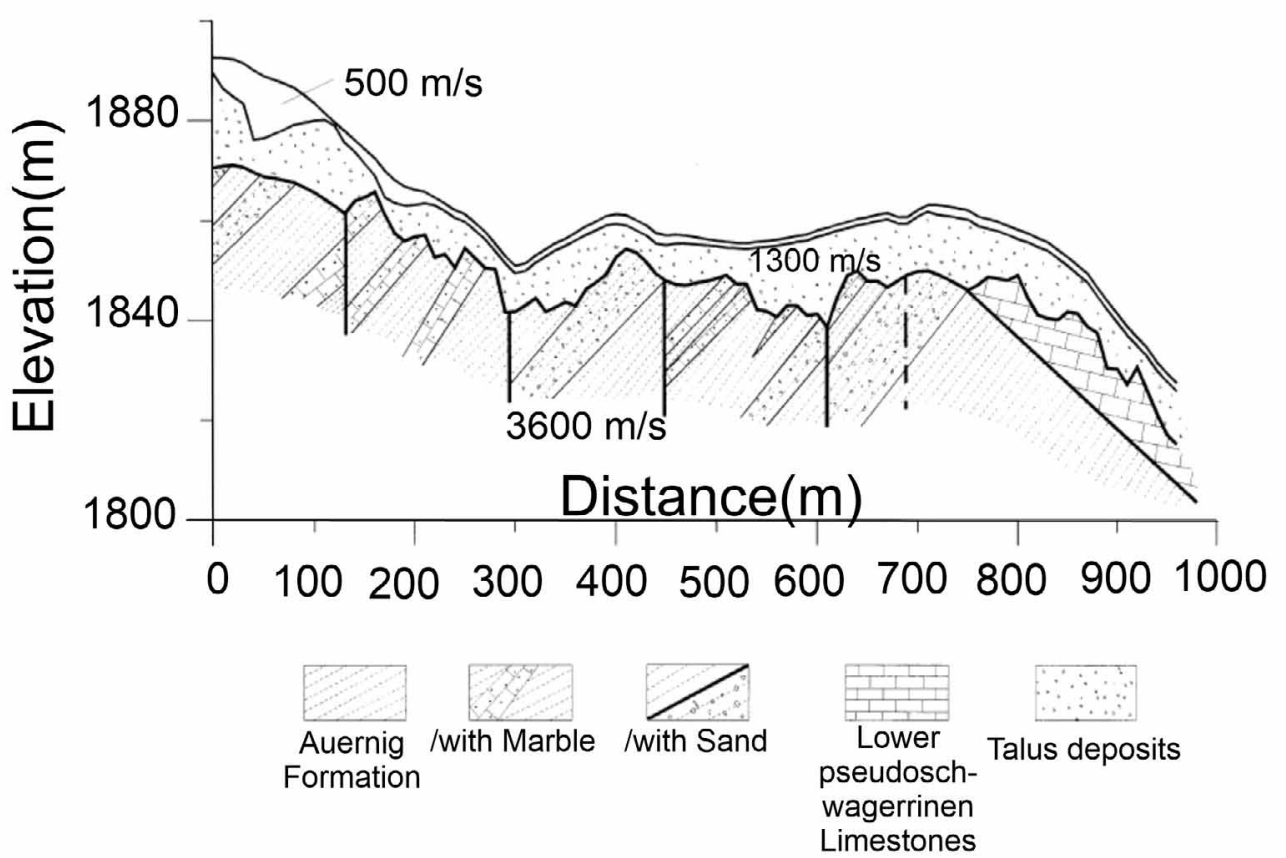

Figure 10. Cross-section of seismic profile modeled using the GRM method [Mauritsch et al., 2000].

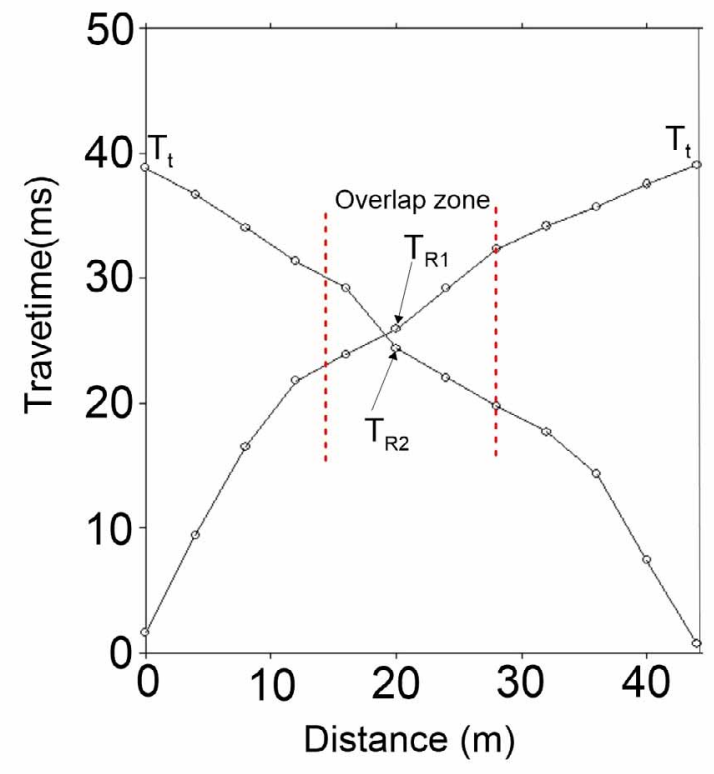

Figure 11. The arrival time plot resulting from forward and reverse shots with an overlap zone limited by the vertical red dashed line [Imani et al., 2021a; Redpath, 1973].

Donohue et al. [2012] employed several algorithms on data obtained from a quick-clay sire in Norway. They applied software GREMIX, which processes data based on the slope-intercept method associated with the DelayTime method and GRM. Due to using the combined processing algorithms, the variations between the unleached clay and the stiffness of quick-clay were visible in the seismic sections. Generally, the delay-time method is not commonly used in landslide investigations due to the compulsion to spread out longer geophysical lines and shorter geophone spacing. 

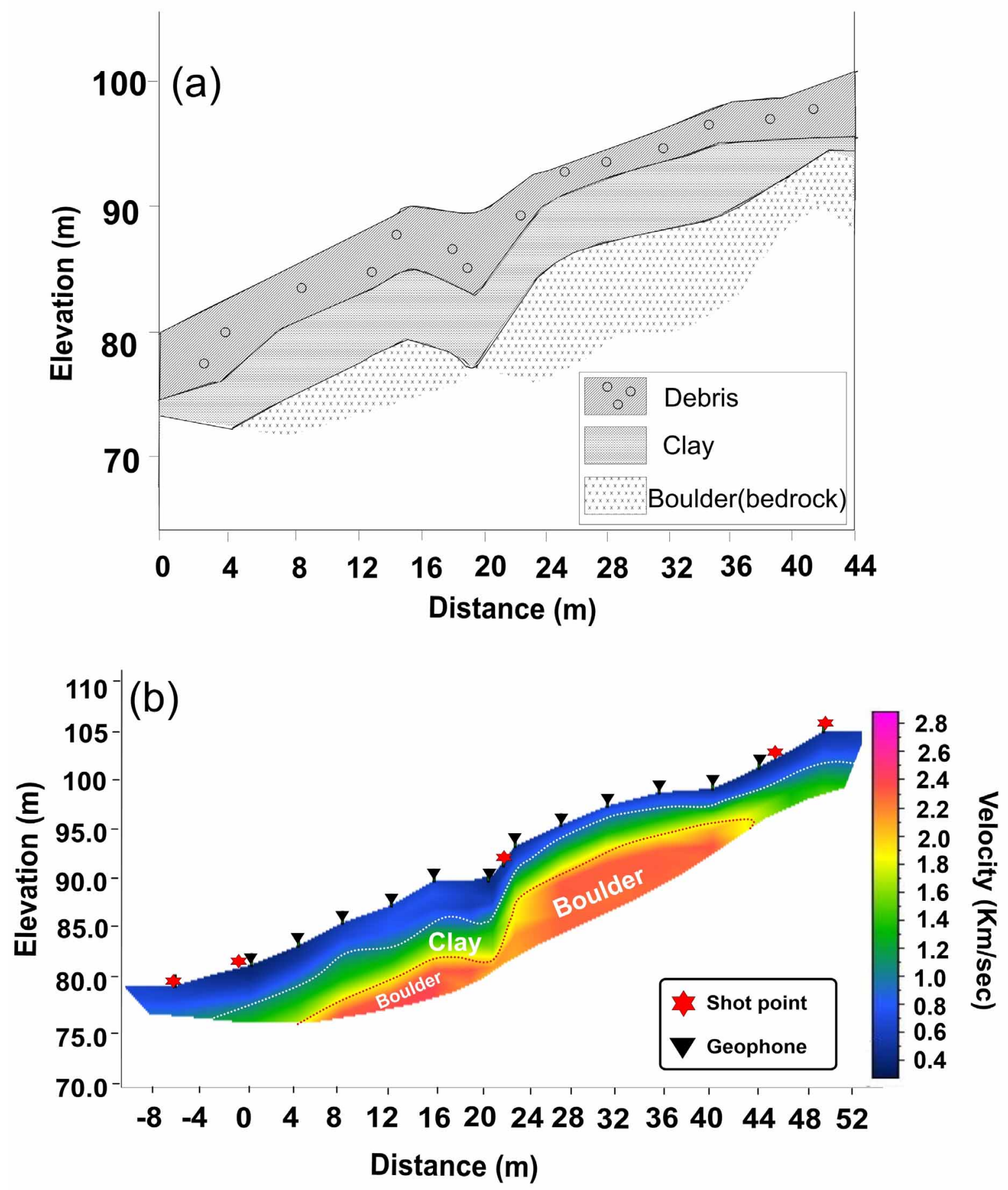

Figure 12. Comparison between (a) the cross-section of the seismic profile (the synthesized model) obtained with the delay-time technique and (b) the inversion model obtained by the refraction tomography processing method [Imani, 2020]. 
The refraction tomography (RT) method is considered as the other processing and interpretation method of refraction data. This technique is regarded as a modern interpreting seismic refraction data that allows being determined lateral variations of P-wave velocity. Tomographic methods are not a unique procedure, and several tomographic methods were used for seismic refraction data analysis [Olsen, 1989; Rubin and Hubbard, 2005]. As the subsurface of the landslide site is discontinuously assumed, refraction tomography can illustrate better images. This method measures the passing energy through materials. Energy received by seismogram is analyzed to find out the media's characters [Stewart, 1991]. Refraction tomographic procedures provide the fittest velocity models by iterative comparison of various velocity features with obtained data to specified resolution created by the operator. As mentioned above, the refraction tomography indicates the velocity variations as a gradient and discrete layer. The gradient of velocity is also known as refraction tomography that applies the raytracing algorithms, including gradual variations of velocity, gradational, and a straightforward interpretation of paths of the energy of the first breaks through underground media [Rucker, 2000].

Furthermore, refraction tomography methods can show the maximum investigation depth with the minimum ray path of the inverse models [Narwold and Owen, 2002]. The RT indicates the gradient of velocity regarding depth. It employs the simulated annealing in which the algorithm applied repeated modeling, and the models can be acceptable according to possible criteria. The criteria allow the algorithm to run away from traveltime deficiencies and non-uniqueness problems in velocity models of subsurface features. The algorithm does not hypothesize the velocity gradient of the subsurface and then can show robust vertical features and lateral gradients. Therefore this method is quite efficient in landslide sites with complex and heterogeneous shallow surface structures [Godio et al., 2006; Narwold and Owen, 2002; Optim, 2001; Pullammanappallil and Louie, 1994] [Optim, 2001]. A seismic ray path set is analyzed to provide a subsurface slice-image. Velocity or attenuation estimation is the main task of refraction tomography [Rubin and Hubbard, 2005]. GRM and refraction tomography methods have an acceptable agreement and can complete the obtained models of landslide areas with details.

The RT procedure provides the fittest models of seismic velocity through the iterative comparison of various velocities with the acquired data to the specified resolution determined by the operator [Narwold and Owen, 2002; Stewart, 1991]. Therefore, RT decreases the drilled borehole numbers to characterize the geological features. Armstrong et al. [2011] used a new approach with a neural network to analyze the synthetic and the observed refraction data and compare GRM and RT results. In this study, more investigations were needed due to the increasing velocity errors with depth that appeared in the results for an unknown reason.

In addition to the processing and interpretation procedures listed above, other methods are applied for data processing in studies of various landslide types. The least-squares method, PS_tomo program [Tryggvason et al., 2002] based on the raytracing method modified by LSQR (algorithm for sparse linear equation and sparse least squares) conjugate gradient solver [Paige and Saunders, 1982], the generalized linear inversion (1998), tomographic grid-based inversion (TGI) and the WET (wave path eikonal travel time) algorithm [Schuster and Quintus-Bosz, 1993] integrated with the Delta-t-V technique, (helpful in decreasing the effect of artifacts into the subsoil) Capizzi and Martorana, [2014] and Gibson et al., [1979] provided excellent results for landslide sites composed of watersaturated clay [Capizzi and Martorana, 2014; Göktürkler et al., 2008; Jacob et al., 2018; Kim et al., 2011; Paige and Saunders, 1982; Wang et al., 2016], while the simultaneous iterative reconstruction technique (SIRT) [Gilbert, 1972] cannot be helpful in high water-saturated material due to the decreasing resolution.

Thus, combined geophysical methods or multidisciplinary procedures are strictly required [Godio et al., 2006; Grandjean and Sage, 2004]. Grit and Kanli [2016] processed the seismic refraction data using the raytracing technique and SIRT to determine the landslide slip plane consisted of coaly shale, conglomerate, sandstone, clay, clayey limestone, and an impermeable layer. However, in this project, the seismic refraction method could not map the high-resolution image of the subsurface structure due to the depth penetration (>30m), while Samyn et al. [2012] obtained good results using simultaneous iterative reconstruction (SIRT) and an algorithm based on a second-order fast marching method (FMM) to compute the travel time using Fresnel wave paths on complex landslides and modeled the 3D seismic velocity using the 3D extension of FMM.

Based on tomographic techniques, the algorithm wavefront-inversion presents high-resolution results in rainfall-induced landslide sites composed of a matrix of sandy-clay with a high weathering rate [Mezerreg et al., 2019; Nwankwo and Ugbena, 2019]. Although this can illustrate the boundaries between the weathered and consolidated refractors in a clear delineation, it does not present powerful functions for processing data in fully saturated material compared to the other RT algorithms. 


\section{Parisa Imani et al.}

\section{The time-lapse seismic refraction tomography (TLSRT)}

The SRT surveys mentioned so far have released static information. These studies were all performed after the sliding mass happened in landslide-prone areas. The obtained information always belongs to the data acquisition time regardless of the gradual changes of geological features and geophysical parameters in the sliding sites. As the water content can influence the surface geometries and interface horizons through weathering, this can play an essential role in triggering landslides. The dynamic activity of the water content can be monitored in considering the velocity changes of the slope investigation.

The control of the dynamic behavior indicates an investigation technique called time-lapse SRT (TLSRT). The time-lapse method leads to a better determination of the landslide situation and slope stability by monitoring the water saturation and surface displacements. This method can also estimate velocity changes in deep hydrocarbon reservoirs and deep investigations [Landrø, 2004; Lumley, 2001]. Few works have operationally employed TLSRT in near-surface applications [Fratta et al., 2005; Gaines et al., 2010; Hilbich, 2010; Imani, 2020; Imani et al., 2021a; Valois, 2016]. Due to the small number of TLSRT studies, all information related to the seismic cross-sections and the landslide types and their compositions are explained below.

Hilbich [2010] attempted to monitor subsurface ice content variations as a sliding reason in alpine terrain. The combined TLSRT and time-lapse electrical resistivity tomography (TLERT) methods were used to determine the changes in subsurface features caused by freezing and melting processes. The SRT models obtained from different seasons were individually interpreted. For more confirmation on SRT models, the seismograms and the first break curves were analyzed. This study confirms the ability of the TLSRT technique to determine ice vanishing and prevents any ambiguities related to the identification of permafrost degradation. Figure 13 illustrates short-term monitoring with different penetration depths of refraction signals caused by the subsurface material characteristics. The sharp refractors typically limit the depth of investigation at the locations with ice-rich permafrost. Moreover, in this study, cluster analysis could estimate the rough mean velocities of the corresponding media by plotting the source-receiver offset against travel times. Additionally, clustering helped indicate the time shifts related to the surface, including ice content and slight velocity variations.

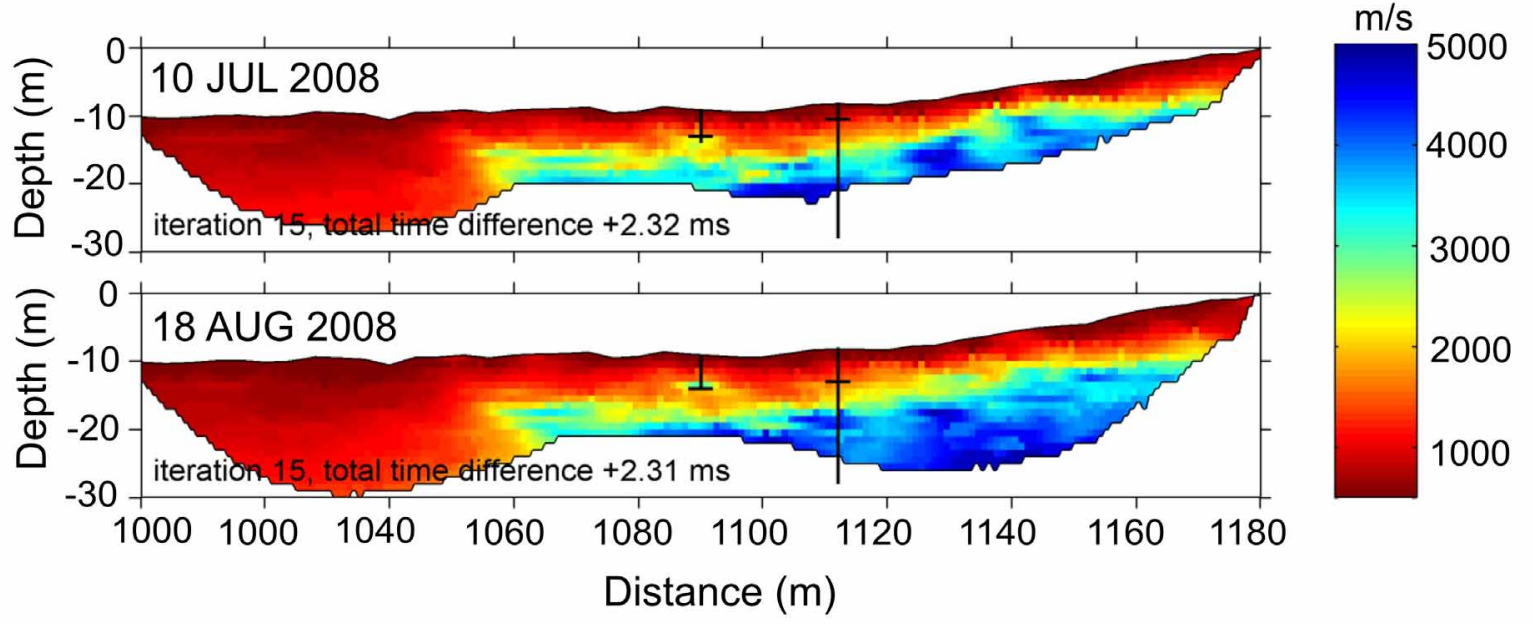

Figure 13. Comparison of seismic cross-section inversions modeled from the two different dates. Vertical black lines show the borehole locations [Hilbich, 2010].

Therefore, the TLSRT method successfully presented the significant relationships between the two models obtained from the two various dates.

Whiteley et al. [2019] proposed a workflow with long-term TLSRT to reduce the sources of potential errors while preserving the variations in subsurface structures in a landslide site placed in the UK. They successfully demonstrated the ability of seismic velocity contrasts to illustrate moisture contents in shallow depths. Wolter et 
al. [2020] monitored the deformation changes of deep-seated gravitational slopes in the long-term and short-term by combining drilling information, surface geomorphology, cosmogenic nuclide dating, TLSRT, and displacement monitoring data. They evaluated the slope instability in the long-term.

In addition to determining the velocity of materials, TLSRT is also successful in illustrating the irregularity of interfaces. Figure 14 proves the TLSRT method's ability to depict velocity variations in different water saturation amounts, boundary shapes, signal attenuation, and the probability of weathering [Imani, 2020; Imani et al., 2021a]. This project was conducted on a mountainous and subtropical area in Hangzhou city, China, to characterize the sliding factors. The high signal attenuation mainly presented can be attributed to the saturation and porosity amount.

Hilbich [2010]; Imani [2020] processed and interpreted the individual inversion images. To better understand the time-lapse SRT from the individual inversion models, the seismograms recorded by various shots are overlapped to compare the time shifts that occurred on different dates. As shown in Figure 15, the time shifts of the first breaks of the August comparison with July are clearly observed at about 3-8 ms [Hilbich, 2010]. The lesser correspondence between the two seismograms occurred due to a lower refractor depth caused by different amounts of saturation.
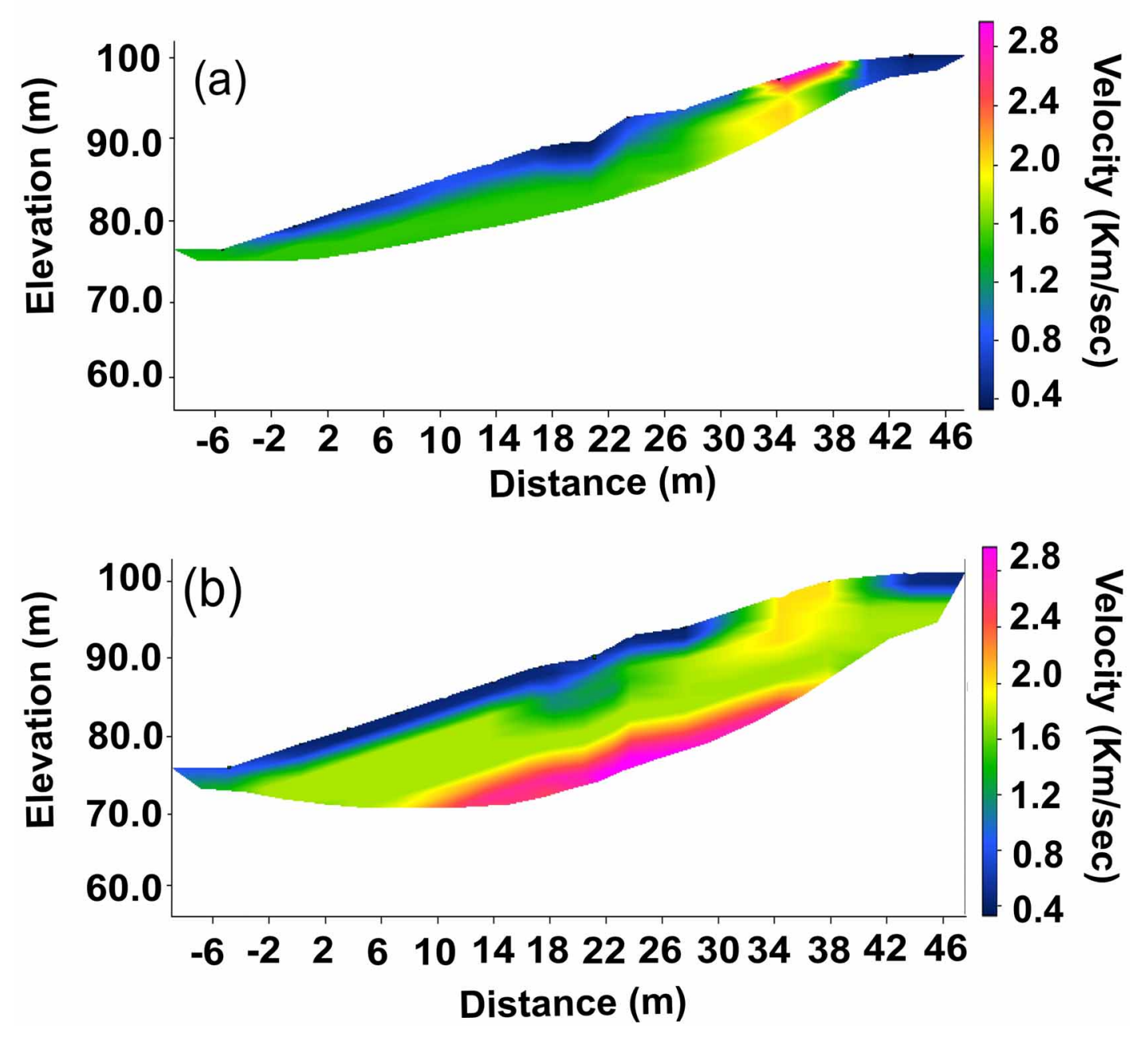

Figure 14. Time-lapse SRT (TLSRT) inversion models mapped from the two different datasets. (a) Cross-section of the seismic profile modeled by data collected in a wet stage. (b) Cross-section of the seismic profile modeled by data collected in a dry stage [Imani, 2020]. 


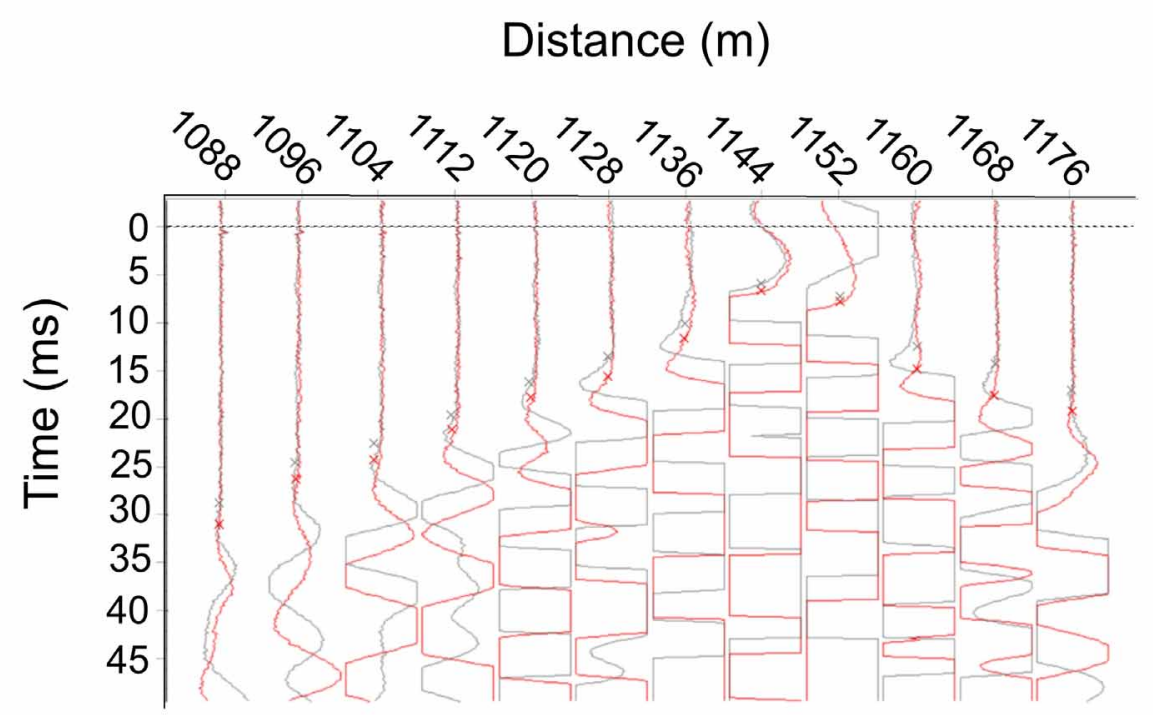

Figure 15. Comparison of the waveforms of the travel times collected in July (gray) and August (red) 2008 [Hilbich, 2010].

\section{Discussion}

A seismic refraction tomography is a powerful tool in landslide studies as one of the near-surface geophysical methods. The case histories reported in this review have discussed the advantages and disadvantages of the seismic refraction method focusing on seismic refraction tomography in different landslide types with various amounts of water saturation (Table 2). Most of the studies (41\%) have been performed on slides and flows types, and the minimum investigation (5\%) belongs to deep-seated studies. Furthermore, $45 \%$ and $20 \%$ of studies reviewed in this paper have been conducted at high saturation and low saturation areas, respectively. The SRT method can delineate the failure surface depth, map the velocity model, determine the boundary between the unstable landslide mass and bedrock, and distinguish the lateral extent of landslide and the weathered bedrock [Narwold and Owen, 2002; Ng et al., 2015]. Reliable subsurface information can be obtained from the high-velocity contrasts between sliding mass and bedrock [Chen et al., 2019a].

\begin{tabular}{cccc} 
Landslide type & $\%$ & Water saturation & $\%$ \\
\hline Slides and flows & 41 & High saturation & 45 \\
\hline Complex & 12 & Moderate saturation & 20 \\
\hline Falls & 12 & Low saturation & \\
\hline Creep & 12 & & \\
\hline Quick-clays & 9 & & \\
\hline Deep-seated & 5 & & \\
\hline No info. & 9 & & \\
\hline
\end{tabular}

Table 2. Variety of investigated landslide types in the present paper and studies conducted at landslide sites with different water saturation amounts.

When the landslide site includes insufficient velocity contrast and a low layer thickness, or when the low layer velocity is less than the upper layer velocity, SRT cannot identify the specific layers [Redpath, 1973] or various rock types [Ng et al., 2015]. The SRT is also unsuitable for investigating very complicated geological features [Ferrucci 


\section{Applications of SRT for landslide monitoring}

et al., 2000]. The seismic velocities change widely due to the variety, compaction, and saturation of subsurface materials [Al-Saigh and Al-Dabbagh, 2010]. These are the main reasons why the SRT cannot be applied individually. Researchers strongly recommend integrating the SRT data to direct or indirect data to obtain more reliable and accurate results. [Mauritsch et al., 2000; Ng et al., 2015; Travelletti et al., 2010].

Considering the problems in which the sliding mechanism is almost ambiguous, those studies that apply the combined geophysical methods in landslide investigations have been more successful. In general, there are the two joint inversion data techniques: the first is the application of hydrogeological properties to link the two various geophysical characteristics [Abubakar et al., 2012; Hamdan and Vafidis, 2013], and the second involves the application of structural properties as a usual factor in the two geophysical models [Abubakar et al., 2012; De Nardis et al., 2005; Gallardo and Meju, 2004; Hamdan and Vafidis, 2013]. The joint inversion method is commonly performed utilizing the synthesized data, and then the same technique is employed to investigate the in-field data [Perrone et al., 2014].

Table 1 presents a collection of joint inversion studies applied for landslide investigations. The data obtained from the joint inversion technique can be the main challenge in the future for geophysicists to get the most suitable subsurface model. It is possible to apply cheaper and more efficient geophysical procedures after testing the more applicable and efficient joint inversion methods. Therefore, there is no necessity to compare the used invasive and direct methods and geophysical results. As shown in Figure 16, the majority of the studies (45\%) reviewed in this paper applied the SRT and electrical tomography data joint inversion, particularly in water-saturated investigations [Bekler et al., 2011; Bichler et al., 2004; Capizzi and Martorana, 2014; Donohue et al., 2012; Godio et al., 2006; Göktürkler et al., 2008; Havenith et al., 2000; Hilbich, 2010; Imani, 2020; Imani and Tian, 2018; Imani et al., 2021b; Jongmans et al., 2009; Karslı et al., 2017; Kim et al., 2011; Kul Yahşi and Ersoy, 2018; Le Roux et al., 2011; Mauritsch et al., 2000; Mezerreg et al., 2019; Nwankwo and Ugbena, 2019; Ostrowski and Lasocki, 2018; Otto and Sass, 2006; Samyn et al., 2012; Solberg et al., 2012; Yilmaz and Kamaci, 2018]. Among electrical methods, electrical resistivity tomography (ERT) is of great importance in landslide studies. Although, Resistivity data are mainly affected by porosity, weathering rate, pore water pressure, water contents, and mineral particles, the ERT technique can illustrate the landslide structure and lateral extent in detail. Despite the success of ERT in landslide projects, Ostrowski and Lasocki [2018] mentioned that compared to SRT, ERT could not recognize unaffected materials from colluvium.

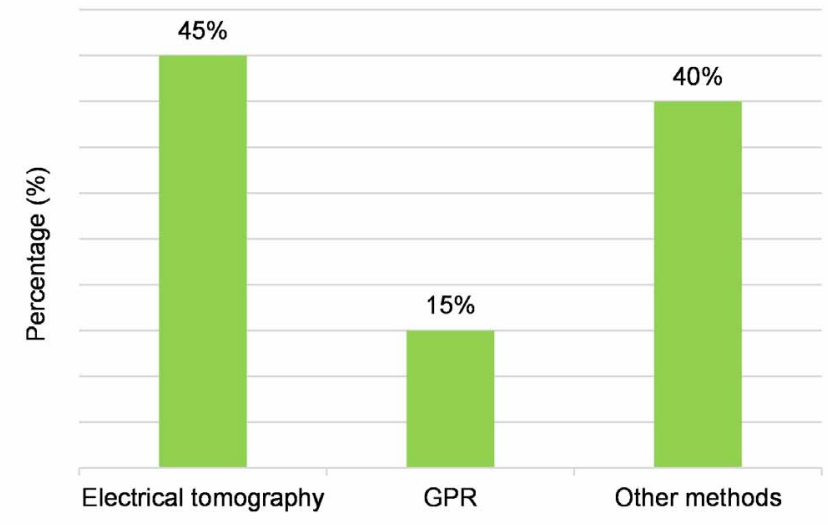

Figure 16. Contribution of different geophysical techniques integrated with SRT in landslide studies.

Only a few examples (15\%) combined with the GPR technique have been reported [Bichler et al., 2004; Otto and Sass, 2006]. Although the GPR signal penetration depth is insufficient in landslide investigations due to scattering energy in heterogeneous sites, it is often used to determine the first subsurface layer. Besides electrical techniques and GPR, the studies (40\%) considered in the review have used other methods. A few projects have illustrated a suitable integration between gravity and the seismic refraction results obtained from rockfall type [Jacob et al., 2018]. The seismic reflection method has been combined with SRT in particular examples [Adamczyk et al., 2013; Bichler et al., 2004; Ferrucci et al., 2000; Grit and Kanli, 2016; Karslı et al., 2017; Kim et al., 2011; Malehmir et al., 


\section{Parisa Imani et al.}

2013b; Travelletti et al., 2010; Wang et al., 2016]. Due to presenting high-resolution results using the reflection method in the literature, this technique appears more powerful and successful than SRT [Grit and Kanli, 2016]. In addition, the reflection method can illustrate the complex geometry structure with more details in structures compared with SRT [Ferrucci et al., 2000].

This paper also highlights that the TLSRT method has been applied in very few examples. As already discussed, this can be chiefly referred back to the intrinsic limitation of the SRT method to show the structures in detail, the software abilities, and the analysis of data. However, due to its ability to present the shape of refractors and the weathered structures, it is suggested by some research [Imani, 2020] to monitor the boundaries of TLSRT. The possibility of locating the borehole spots, and receiver and shot points for the next measurements should also be considered in monitoring projects. This context also highlights the hardship of TLSRT data processing. Based on Imani [2020]; Whiteley et al. [2019], and Hilbich [2010], there is no powerful software for processing TLSRT data that can quantify the velocity changes as a function of the variations in the hydrogeological parameters. This problem can be solved by individually interpreting models, extending the monitoring time, and increasing survey times.

\section{Conclusions}

After careful deliberation of the research since the year 2000 involving every type of landslide phenomenon, we concluded that seismic refraction tomography (SRT) presents reliable and accurate information on the wave velocity contrast of different geological structures associated with sliding material and bedrock. The SRT is employed to characterize the physical properties of materials within landslides, delineate the boundaries between subsoil horizons and surface failures, and determine the landslide lateral extension and depth. Based on the SRT results, investigating the high water content in low-velocity layers in landslide-prone areas is essential to prevent future sliding events.

Velocity models illustrate the low and high-velocity values corresponding to landslide materials and bedrock, respectively. As already explained, this paper highlighted the significant SRT method limitations that can be improved using combined geophysical techniques or multidisciplinary methods, such as geotechnical and geological approaches, mainly when highly saturated materials are studied. The reliability of the obtained results likely does not depend on the type of landslide. Although, like the other geophysical techniques, the method presents preliminary results in which the velocity contrasts are masked. SRT appears to act as a well-consolidated tool for characterizing the sliding extent, saturated materials, and boundaries of all landslide types.

The SRT data quality does not appear to be influenced by the measurement equipment applied, but the survey strategy should be carefully considered. Although TLSRT has been introduced as a successful method in the reviewed studies, there are only a few examples in recent monitoring projects. Additionally, in interpreting TLSRT data, the geotechnical and hydrogeological parameters, such as the amount of porosity, the amount of saturation, and the pore water pressure cannot be shown in the quantitative results. Finally, the information presented in this study allows us to apply seismic refraction tomography as an efficient and reliable tool that can illustrate hydrogeological and geological hazards in the past, present, and future phases of sliding sites.

\section{References}

Abraham, J.D., and J.E. Lucius (2004). Direct current resistivity profiling to study distribution of water in the unsaturated zone near the Amargosa Desert Research Site, Nevada. In Open-File Report.

Abramson, L.W., T.S. Lee, S. harma, and G. M. Boyce (2002). Slope stability and stabilization methods, (New York: John Wiley and Sons, Inc.).

Abubakar, A., G. Gao, T.M. Habashy, and J. Liu (2012). Joint inversion approaches for geophysical electromagnetic and elastic full-waveform data, Inverse Probl., 28, 19.

Adamczyk, A., M. Malinowski, and A. Malehmir (2013). Application of first-arrival tomography to characterize a quick clay landslide site in Southwest Sweden, Acta Geophys., 61, 1057-1073.

Al-Heety, A.J.R., and Z. M. Shanshal (2015). Integration of seismic refraction tomography and electrical resistivity tomography in engineering geophysics for soil characterization, Arabian J. Geosci., 9, 73. 


\section{Applications of SRT for landslide monitoring}

Al-Saigh, N.H., and T.H. Al-Dabbagh (2010). Identification of landslide slip-surface and its shear strength: A new application for shallow seismic refraction method, J. Geol. Soc. India, 76, 175-180.

Azwin, I.N., R. Saad, and M. Nordiana (2013). Applying the Seismic Refraction Tomography for Site Characterization, APCBEE Procedia 5, 227-231.

Baldi, P., N. Cenni, M. Fabris, and A. Zanutta (2008). Kinematics of a landslide derived from archival photogrammetry and GPS data, Geomorphology, 102, 435-444.

Baron, I., and R. Supper (2013). Application and reliability of techniques for landslide site investigation, monitoring and early warning - outcomes from a questionnaire study, Nat. Hazard. Earth Syst. Sci., 3, 3157-3168.

Bárta, J., D. Dostál, V. Beneš, and M. Tesar (2005). Application of Geophysical Methods in The Study of Landslide Movements, Taking Into Account Geological Conditions in The Study Mountains, Acta Geody. et Geomat., 2, 121-129.

Bekler, T., Y.L. Ekinci, A. Demirci, A.E. Erginal, and C. Ertekin (2011). Characterization of a Landslide using Seismic Refraction, Electrical Resistivity and Hydrometer Methods, Adatepe - Çanakkale, NW Turkey, J. Environ. Eng. Geophys., 16, 115-126.

Bichler, A., P. Bobrowsky, M. Best, M. Douma, J. Hunter, T. Calvert, and R. Burns (2004). Three-dimensional mapping of a landslide using a multi-geophysical approach: the Quesnel Forks landslide. Landslides, 1, 29-40.

Bogoslovsky, V.A., and A.A. Ogilvy (1977). Geophysical methods for the investigation of landslides, Geophysics, 42 , 562-571.

Brooke, J.P. (1973). Geophysical investigations of a landslide near San Jose, California, Geoexploration, 11, 61-73.

Bruckshaw, J.M. (1941). Geophysical Prospecting for Oil. Nature, 148, 151-152.

Bruno, F., and F. Martillier (2000). Test Of High-Resolution Seismic Reflection And Other Geophysical Techniques On The Boup Landslide In The Swiss Alps, Surv. Geophys., 21, 335-350.

Capizzi, P., and R. Martorana (2014). Integration of constrained electrical and seismic tomographies to study the landslide affecting the cathedral of Agrigento, J. Geophys. Eng., 11.

Chen, Q., S. Zhang, S. Chang, B. Liu, J. Liu, and J. H. Long (2019a). Geophysical Interpretation of a Subsurface Landslide in the Southern Qinshui Basin, J. Environ. Eng. Geophys., 24, 433-449.

Chen, W., H. Hong, M. Panahi, H. Shahabi, Y. Wang, A. Shirzadi, S. Pirasteh, A.A. Alesheikh, K. Khosravi, S. Panahi, et al. (2019b). Spatial Prediction of Landslide Susceptibility Using GIS-Based Data Mining Techniques of ANFIS with Whale Optimization Algorithm (WOA) and Grey Wolf Optimizer (GWO), Appl. Sci., 9, 3755.

Cummings, D., and B.R. Clark (1988). Use of Seismic Refraction and Electrical Resistivity Surveys in Landslide Investigations, Environ. Eng. Geosci., xxv, 459-464.

De Nardis, R., E. Cardarelli, and M. Dobroka (2005). Quasi-2D hybrid joint inversion of seismic and geoelectric data, Geophys. Prospect., 53, 705-716.

Donohue, S., M. Long, P. O-Connor, T. Eide Helle, A. Aspmo Pfaffhuber, and M. Rømoen (2012). Multi-method geophysical mapping of quick clay, Near Surf. Geophys., 10, 207-219.

Edge, and Laby (1931). The Principles and Practice of Geophysical Prospecting: being the Report of the Imperial Geophysical Experimental Survey, Nature, 128, 427-428.

Ferrucci, F., M. Amelio, M. Sorriso-Valvo, and C. Tansi (2000). Seismic prospecting of a slope affected by deep-seated gravitational slope deformation: the Lago Sackung, Calabria, Italy, Eng. Geol., 57, 53-64.

Fratta, D., K. Alshibli, W. Tanner, and L. Roussel (2005). Combined TDR and P-Wave Velocity Measurements for the Determination of In Situ Soil Density\&mdash;Experimental Study, Geotech. Test. J., 28, 553-563.

Gaines, D., G.S. Baker, S.S. Hubbard, D. Watson, S. Brooks, and P. Jardine (2010). Detecting Perched Water Bodies Using Surface-Seismic Time-Lapse Traveltime Tomography, In Advance in Near-surface Seismology and Ground-penetrating Radar, 415-428.

Gallardo, L.A., and M. A. Meju (2004). Joint two-dimensional DC resistivity and seismic travel time inversion with cross-gradients constraints, J. Geophys. Res.: Solid Earth, 109.

Gibson, B.S., M.E. Odegard, and G.H. Sutton (1979). Nonlinear least-squares inversion of traveltime data for a linear velocity-depth relationship, Geophysics, 44, 185-194.

Gilbert, P. (1972). Iterative methods for the three-dimensional reconstruction of an object from projections, J. Theo. Biol. 36, 105-117.

Glade, T., P. Stark, and R. Dikau (2005). Determination of potential landslide shear plane depth using seismic refraction-a case study in Rheinhessen, Germany, Bull. Eng. Geol. Environ., 64, 151-158. 


\section{Parisa Imani et al.}

Godio, A., C. Strobbia, and G. De Bacco (2006). Geophysical characterisation of a rockslide in an alpine region, Eng. Geol., 83, 273-286.

Göktürkler, G., Ç. Balkaya, and Z. Erhan (2008). Geophysical investigation of a landslide: The Altındağ landslide site, İzmir (western Turkey), J. Appl. Geophys., 65, 84-96.

Grandjean, G., and S. Sage (2004). JaTS: a fully portable seismic tomography software based on Fresnel wavepaths and a probabilistic reconstruction approach, Comput. Geosci., 30, 925-935.

Grit, M., and A.I. Kanli (2016). Integrated Seismic Survey for Detecting Landslide Effects on High Speed Rail Line at Istanbul-Turkey, Open Geosci., 8, 161.

Hack, R. (2000). Geophysics for slope staibility, J. Surv. Geophys., 21, 423-448.

Hagedoorn, J.G. (1959). The plus-minus method of interpreting seismic refraction sections, Geophys. Prospect., 7, 158-182.

Hagedoorn, J.G. (1962). On: Hawkin's paper “ The Reciprocal Method of Routin Shallow Seismic Refraction Investigations” (Geophysics, December, 1961, PP. 806-819), Geophysics, 27, 534-535.

Hamdan, H.A., and A. Vafidis (2013). Joint inversion of 2D resistivity and seismic travel time data to image saltwater intrusion over karstic areas, Environ. Earth Sci., 68, 1877-1885.

Hatherly, P.J. (1980). Computer Processing of Seismic Refraction Data, Explor. Geophys., 11, 69-74.

Havenith, H.-B., D. Jongmans, E. Faccioli, K. Abdrakhmatov, and P. -Y. Bard (2002). Site Effect Analysis around the Seismically Induced Ananevo Rockslide, Kyrgyzstan, Bull. Seismol. Soc. Am., 92, 3190-3209.

Havenith, H.B., D. Jongmans, K. Abdrakhmatov, P. Trefois, D. Dervaux, and I.A. Torgoev (2000). Geophysical Investigations of Seismically Induced Surface Effects: Cace Study of a Landslide in the Suusamyr Valley, Kygyzstan, Surv. Geophys., 21, 351-370.

Hawkins, L.V. (1961). The reciprocal method of routine shallow seismic refraction investigations, Geophysics, 26, 806-819.

Heincke, B. (2005). Determination of 3-D fracture distribution on an unstable mountain slope using georadar and topographic seismic refraction techniques (Zurich: Swiss Federal Institute of Technology).

Heincke, B., H. Maurer, A.G. Green, H. Willenberg, T. Spillmann, and L. Burlini (2006). Characterizing an unstable mountain slope using shallow 2D and 3D seismic tomography, Geophysics 71, B241-B256.

Heincke, B., T. Günther, E. Dalsegg, J.S. Rønning, G.V. Ganerød, and H. Elvebakk (2010). Combined three-dimensional electric and seismic tomography study on the Åknes rockslide in western Norway, J. Appl. Geophys., 70, 292-306.

Hibert, C., G. Grandjean, A. Bitri, J. Travelletti, and J. -P. Malet (2012). Characterizing landslides through geophysical data fusion: Example of the La Valette landslide (France), Eng. Geol., 128, 23-29.

Hilbich, C. (2010). Time-lapse refraction seismic tomography for the detection of ground ice degradation, The Cryosphere, 4, 243-259.

Imani, P. (2020). Landslide investigations and monitoring by Electrical Resistivity and Seismic Refraction Tomography in a case study, PhD thesis, In School of Erath Sceinces (Zhejiang University), p. 153.

Imani, P., and G. Tian (2018). Introduction of the Most Applicable Geophysical Methods on Landslide Studies and Application of ERT and SRT: Case Study, In 8th International Conference Environmental and Engineering Geophysics (Hangzhou, China: Zhejiang University).

Imani, P., G. Tian, and A.A. El-Raouf (2021a). Assessment of spatiotemporal changes in water contents of landslide zone by geophysical methods: a case study, Arabian J. Geosci., 14, 1380.

Imani, P., G. Tian, S. Hadiloo, and A.A. El-Raouf (2021b). Application of combined electrical resistivity tomography (ERT) and seismic refraction tomography (SRT) methods to investigate Xiaoshan District landslide site: Hangzhou, China, J. Appl. Geophys., 184, 104236.

Jacob, T., K. Samyn, A. Bitri, F. Quesnel, T. Dewez, P. Pannet, and B. Meire (2018). Mapping sand and clay-filled depressions on a coastal chalk clifftop using gravity and seismic tomography refraction for landslide hazard assessment, in Normandy, France, Eng. Geol., 246, 262-276.

Jongmans, D., G. Bièvre, F. Renalier, S. Schwartz, N. Beaurez, and Y. Orengo (2009). Geophysical investigation of a large landslide in glaciolacustrine clays in the Trièves area (French Alps), Eng. Geol., 109, 45-56.

Jongmans, D., and S.p. Garambois (2007). Geophysical investigation of landslides: a review, Bull. de la Soc. Géol. de France, 178, 101-112.

Kaminskiy, A.E. (2013). Program of two-dimensional seismotomography data processing and interpretation, User's Manual, In ZondST2D softw., version 4 (Saint-Petersburg.). 


\section{Applications of SRT for landslide monitoring}

Karslı, H., G. Vanlı Şenkaya, M. Şenkaya, and R. Güney (2017). Investigation of soil structure in Uzungöl settlement area by Shallow Seismic Methods, Eurasian J. Soil Sci., 6, 134-143.

Kassab, M.A., and A. Weller (2015). Study on P-wave and S-wave velocity in dry and wet sandstones of Tushka region, Egypt, Egyptian J. Pet., 24, 1-11.

Kim, M.-I., J.-S. Kim, N.-W. Kim, and G.-C. Jeong (2011). Surface geophysical investigations of landslide at the Wiri area in southeastern Korea, Environ. Earth Sci., 63, 999-1009.

Kisunezaki, C. (1965). In Situ Determination of Variation of Poisson's Ratio in Granite Accompanied by Weathering Effect and its Significance in Engineering Projects, Bull. Disaster Prev. Res. Inst., 15, 19-41.

Kul Yahşi, B., and H. Ersoy (2018). Site characterization and evaluation of the stability of the Yesilyurt Landslide (Trabzon, NE Turkey) using back analysis method, J. Geophys. Eng., 15, 927-937.

Landrø, M., A.K. Nguyen, and H. Mehdizadeh (2004). Time lapse refraction seismic - a tool for monitoring carbonate fields? In 74th SEG Meeting (Expanded Abstract, Denver, Colorado), pp. 1-4.

Lankston, R.W. (1989). The seismic refraction method: A viable tool for mapping shallow targets into the 1990s, Geophysics, 54, 1535-1542.

Le Roux, O., D. Jongmans, J. Kasperski, S. Schwartz, P. Potherat, V. Lebrouc, R. Lagabrielle, and O. Meric (2011). Deep geophysical investigation of the large Séchilienne landslide (Western Alps, France) and calibration with geological data, Eng. Geol., 120, 18-31.

Lumley, D.E. (2001). Time-lapse seismic reservoir monitoring. Geophysics, 66, 50-53.

Malehmir, A., M.U. Saleem, and M. Bastani (2013a). High-resolution reflection seismic investigations of quick-clay and associated formations at a landslide scar in southwest Sweden, J. Appl. Geophys., 92, 84-102.

Malehmir, A., S.S. Romero, C. Shan, E. Lundberg, C. Juhlin, M. Bastani, L. Persson, C. Krawczyk, U. Polom, A. Adamczyk, et al. (2013b). A multidisciplinary geophysical and geotechnical investigation of quick clay landslides in Sweden, In SEG Technical Program Expanded Abstracts 2013, pp. 1254-1258.

Mantovani, F., R. Soeters, and C.J. Van Westen (1996). Remote sensing techniques for landslide studies and hazard zonation in Europe, Geomorphology, 15, 213-225.

Mauritsch, H.J., W. Seiberl, R. Arndt, A. Römer, K. Schneiderbauer, and G.P. Sendlhofer (2000). Geophysical investigations of large landslides in the Carnic Region of southern Austria, Eng. Geol., 56, 373-388.

McCann, D.M., and A. Forster (1990). Reconnaissance geophysical methods in landslide investigations, Eng. Geol., $29,59-78$.

Metternicht, G., L. Hurni, and R. Gogu (2005). Remote sensing of landslides: An analysis of the potential contribution to geo-spatial systems for hazard assessment in mountainous environments, Remote Sens. Environ., 98, 284303.

Mezerreg, N.E.H., F. Kessasra, Y. Bouftouha, H. Bouabdallah, N. Bollot, A. Baghdad, and R. Bougdal (2019). Integrated geotechnical and geophysical investigations in a landslide site at Jijel, Algeria, J. Afr. Earth Sci., 160, 103633.

Musgrave, A.W. (1967). Seismic Refraction Prospecting.

Narwold, C.F., and W.P. Owen (2002). Seismic refraction analysis of landslides, In The Geophysics conference (California, USA).

Ng, S.M., M.A. Mohamad Ismail, T.C. Ghaun, and Y. Rais (2015). Subsurface Characterization Using Seismic Refraction and Borehole Drilling for Slope Stability Study, The Electron. J. Geotech. Eng., 20.

Nolet, G. (1987). Seismic Tomography. (Springer Netherlands).

Nwankwo, C.N., and G.K. Ugbena (2019). Electrical Resistivity and Seismic Refraction Methods of Investigating a Landslide Area: A Case Study of Elu Community, Abia State, Nigeria, World Sci. News, 129, 135-146.

Olsen, K.B. (1989). A stable and flexible procedure for the inverse modeling of seismic first arrivals, Geophys. Prospect., 37, 455-465.

Optim (2001). User’s manual SeisOpt ${ }^{\mathrm{R}} @ 2 \mathrm{D}^{\mathrm{TM}}$ Version 2.8, Optim LLC, UNR-MS 174, 1664 N. Virginia St., Reno, Nevada; 2001.

Ostrowski, S.Z., and Lasocki, M. (2018). Massive Landslide Characterization Using Refraction Seismic and Electric Tomography, In 24th European Meeting of Environmental and Engineering Geophysics, September (European Association of Geoscientists \& Engineers), 1-5.

Otto, J.C., and O. Sass (2006). Comparing geophysical methods for talus slope investigations in the Turtmann valley (Swiss Alps), Geomorphology, 76, 257-272.

Ozcep, F., E. Erol, F. Saraçoğlu, and M. Haliloğlu (2012). Seismic landslide analysis: Gurpinar (Istanbul) as a case 


\section{Parisa Imani et al.}

history, Environ. Earth Sci., 66, 1-14.

Paige, C.C., and M.A. Saunders (1982). LSQR: An Algorithm for Sparse Linear Equations and Sparse Least Squares. ACM Trans, Math. Softw., 8, 43-71.

Palmer, D. (1980). The Generalized Reciprocal Method of Seismic Refraction Interpretation.

Palmer, D. (1981). An Introduction to the generalized reciprocal method of seismic refraction interpretation, Geophysics, 46, 1508-1518.

Palmer, D.F., and S.L. Weisgarber (1988). Geophysical Survey of the Stumpy Basin Landslide, Ohio, Environ. Eng. Geosci., xxv, 363-370.

Pazzi, V., S. Morelli, and R. Fanti (2019). A Review of the Advantages and Limitations of Geophysical Investigations in Landslide Studies, Int. J. Geophys., 2019, 27.

Perrone, A., V. Lapenna, and S. Piscitelli (2014). Electrical resistivity tomography technique for landslide investigation: A review, Earth Sci. Rev., 135, 65-82.

Pullammanappallil, S.K., and J.N. Louie (1994). A generalized simulated-annealing optimization for inversion of first-arrival times, Bull. Seismol. Soc. Am., 84, 1397-1409.

Pullan, S.E., and H.A. MacAulay (1987). An in-hole shotgun source for engineering seismic surveys, Geophysics, 52, 985-996.

Rashed, M.A. (2009). GDP: A new source for shallow high-resolution seismic exploration, J. Appl. Geophys., 68, 243248.

Redpath, B.B. (1973). Seismic Refraction Exploration for Engineering Site Investigations, (Technical Report E-734, US Army Engineer Waterways Experiment Station Explosive Excavation Research Laboratory, Livermore).

Rubin, Y., and S.S. Hubbard (2005). Hydrogyophysics, (Dordrecht, the Netherlands Springer).

Rucker, M.L. (2000). Applying the siesmic refraction technique to exploration for transportation facilities in geophysics. In The First International Conference on the Application of Geophysical Methodologies to Transportation Facilities and Infrastructure, St. Louis, Missouri, 11-15 December, pp. 1-13.

Samyn, K., J. Travelletti, A. Bitri, G. Grandjean, and J.P. Malet (2012). Characterization of a landslide geometry using 3D seismic refraction traveltime tomography: The La Valette landslide case history, J. Appl. Geophys., 86, 120132.

Scaioni, M., L. Longoni, V. Melillo, and M. Papini (2014). Remote Sensing for Landslide Investigations: An Overview of Recent Achievements and Perspectives, Remote Sens., 6.

Schuster, G.T., and A. Quintus-Bosz (1993). Wavepath eikonal traveltime inversion: Theory, Geophysics, 58, 13141323.

Solberg, I.-L., L. Hansen, J.S. Rønning, E.D. Haugen, E. Dalsegg, and J.F. Tønnesen (2012). Combined geophysical and geotechnical approach to ground investigations and hazard zonation of a quick clay area, mid Norway, Bull. Eng. Geol. Environ., 71, 119-133.

Sompotan, A.F., L.A. Pasasa, and R. Sule (2011). Comparing Models GRM, Refraction Tomography and Neural Network to Analyze Shallow Landslide, J. Eng. Technol. Sci., 161-172.

Stewart, R.R. (1991). Exploration seismic tomography: fundamentals, (Tulsa: Society of Exploration Geophysicists), $1-1$.

Telford. W.M., L.P. Gerald, and R.E. Sheriff (1990). Applied Geophysics, (USA: The Press Syndicate of University of Cambridge).

Tomás, R., A. Abellán, M. Cano, A. Riquelme, A.J. Tenza-Abril, F. Baeza-Brotons, J.M. Saval, and M. Jaboyedoff (2018). A multidisciplinary approach for the investigation of a rock spreading on an urban slope, Landslides, 15, 199217.

Travelletti, J., J. Demand, M. Jaboyedoff, and F. Marillier (2010). Mass movement characterization using a reflexion and refraction seismic survey with the sloping local base level concept, Geomorphology, 116, 1-10.

Tryggvason, A., S.T. Rögnvaldsson, and Ó.G. Flóvenz (2002). Three-dimensional imaging of the P- and S-wave velocity structure and earthquake locations beneath Southwest Iceland. Geophys, J. Int., 151, 848-866.

Uhlemann, S., S. Hagedorn, B. Dashwood, H. Maurer, D. Gunn, T. Dijkstra, and J. Chambers (2016). Landslide characterization using P- and S-wave seismic refraction tomography - The importance of elastic moduli, J. Appl. Geophys., 134, 64-76.

Valois, R., P.-Y. Galibert, R. Guerin, and V. Plagnes (2016). Application of combined time-lapse seismic refraction and electrical resistivity tomography to the analysis of infiltration and dissolution processes in the epikarst of the 


\section{Applications of SRT for landslide monitoring}

Causse du Larzac (France), Near Surf. Geophys., 14, 13-22.

Vanlı Senkaya, G., M. Senkaya, H. Karsli, and R. Güney (2019). Integrated shallow seismic imaging of a settlement located in a historical landslide area, Bull. Eng. Geol. Environ.,.

Ventura, G., G. Vilardo, C. Terranova, and E. B. Sessa (2011). Tracking and evolution of complex active landslides by multi-temporal airborne LiDAR data: The Montaguto landslide (Southern Italy), Remote Sens. Environ., 115, 3237-3248.

Wang, S., A. Malehmir, and M. Bastani (2016). Geophysical characterization of areas prone to quick-clay landslides using radio-magnetotelluric and seismic methods, Tectonophysics, 677-678, 248-260.

Whiteley, J.S., J.E. Chambers, S. Uhlemann, P.B. Wilkinson, and J.M. Kendall (2019). Geophysical Monitoring of Moisture-Induced Landslides: A Review, Rev. Geophys., 57, 106-145.

Wilson, C.D.V. (1983). Reflection Seismology-a Tool for Energy Resource Exploration (2nd edn) by Kenneth H. Waters, Wiley, New York, 1981. No. of pages: xvi 453. Geol. J., 18, 191-192.

Wolter, A., C. Roques, J. Gröble, S. Ivy-Ochs, M. Christl, and S. Loew (2020). Integrated multi-temporal analysis of the displacement behaviour and morphology of a deep-seated compound landslide (Cerentino, Switzerland), Eng. Geol., 270, 105577.

Xu, D., X.-Y. Hu, C.-L. Shan, and R.-H. Li (2016). Landslide monitoring in southwestern China via time-lapse electrical resistivity tomography, Appl. Geophys., 13, 1-12.

Yalcin, A. (2007). The effects of clay on landslides: A case study, Appl. Clay Sci., 38, 77-85.

Yilmaz, O. (1987). Seismic analysis data: Processing, Inversion, and Interpretation of Seismic Data, (Society of Exploraition Geophysics).

Yilmaz, S., and Z. Kamaci (2018). Resistivity and Seismic Refraction Studies on Kısıklı Landslide (Antalya, Turkey), Int. J. Comput. Experimet. Sci. Eng., 4, 9-14.

Zainal Abidin, M.H., R. Saad, F. Ahmad, D.C. Wijeyesekera, and M.F. Tajul Baharuddin (2012). Seismic Refraction Investigation on Near Surface Landslides at the Kundasang area in Sabah, Malaysia, Procedia Eng., 50, 516553.

Parisa Imani and Amr Abd El-Raouf contributed equally to this work as first authors.

*CORRESPONDING AUTHOR: Amr Abd EL-RAOUF,

School of Earth Sciences, Zhejiang University, Zheda Road 38, Hangzhou 310027, China and Geology Department, Faculty of Science, Zagazig University, Zagazig 44519, Egypt;

e-mail:amr_abdelraouf@zu.edu.eg

(c) 2021 the Author(s). All rights reserved.

Open Access. This article is licensed under a Creative Commons Attribution 3.0 International 